\title{
The Co-evolution of Multiply-Informed Dispersal: Information Transfer Across Landscapes from Neighbors and Immigrants
}

Dispersal plays a key role in natural systems by shaping spatial population and evolutionary dynamics. Dispersal has been largely treated as a population process with little attention to individual decisions and the influence of information use on the fitness benefits of dispersal despite clear empirical evidence that dispersal behavior varies among individuals. While information on local density is common, more controversial is the notion that indirect information use can easily evolve. We used an individual-based model to ask under what conditions indirect information use in dispersal will evolve. We modeled indirect information provided by immigrant arrival into a population which should be linked to overall metapopulation density. We also modeled direct information use of density which directly impacts fitness. We show that immigrant-dependent dispersal evolves and does so even when density dependent information is available. Use of two sources of information also provides benefits at the metapopulation level by reducing extinction risk and prolonging the persistence of populations. Our results suggest that use of indirect information in dispersal can evolve under conservative conditions and thus could be widespread. 
1 Alexis S. Chaine ${ }^{1}$, Stéphane Legendre ${ }^{2}$, Jean Clobert ${ }^{1}$

2

3 'Station d'Ecologie Expérimentale du CNRS à Moulis, USR 2936, 2 route du CNRS, 09200

4 Moulis, France

$5 \quad{ }^{2}$ Laboratoire Ecologie \& Evolution, UMR7625, Ecole Normale Supérieure, 46 rue d'Ulm, 75230

6 Paris Cedex 05, France

7

8 Corresponding Author: alexis.chaine@ecoex-moulis.cnrs.fr;

9 Tel: +33561040378; Fax: +33561960851

10 Jean Clobert: jean.clobert@ecoex-moulis.cnrs.fr

11 Stéphane Legendre: legendre@biologie.ens.fr

12 
MULTIPLY-INFORMED DISPERSAL

\section{INTRODUCTION}

Dispersal is a key component of many ecological and evolutionary processes ranging

16 from population dynamics to local adaptation and has been the focus of extensive empirical and

17 theoretical investigation (Clobert et al. 2001; Ronce 2007; Nathan et al. 2008; Clobert et al.

18 2012a). The impact of dispersal on both population dynamics, movement across the landscape,

19 and local adaptation makes it a critical element of understanding how populations are affected by

20 landscape fragmentation and global warming (Chaine \& Clobert 2012). Dispersal has largely

21 been treated as a population level character even though dispersal decisions are fundamentally an

22 individual behavior that should benefit from knowledge of the landscape. Recent empirical

23 evidence suggests that information use in making dispersal decisions and navigating the

24 landscape plays an important role in patterns of dispersal (Bowler \& Benton 2005; Clobert et al.

25 2009; Schmidt, Dall \& Van Gils 2010). Information use would cause a shift in how we view

26 dispersal. Exchanges among populations would no longer represent a random subset of

27 genotypes and might affect local adaptation patterns__Blanchet, Clobert \& Danchin 2010).

28 Dispersers might not spread randomly across the landscape and some populations might receive

29 more or fewer immigrants due to dispersal cost (Bonte et al. 2012). In applied work, if we want

30 to encourage dispersal, we would need to make sure that the key information sources are

31 available or even manipulate information to get the desired level of dispersal_Blanchet et al.

32 2010; Chaine \& Clobert 2012). Yet our fundamental understanding of informed dispersal remains

33 limited (Clobert et al. 2009).

34 The use of information in dispersal decisions has received attention through a limited

35 range of possibilities despite potentially important effects on fitness (Ims \& Hjermann 2001; 
Ronce et al. 2001; Bowler \& Benton 2005; Clobert et al. 2009; Schmidt et al. 2010). Classical ecological (metapopulation) and evolutionary (gene-flow) theory assumes constant dispersal rates with more or less-random movement and no information use (Hanski \& Gaggiotti 2004). At the other extreme, ideal free settlement models assume perfect knowledge of the entire landscape which influences dispersal (Holt \& Barfield 2001). Both approaches are analytically tractable, but biologically unrealistic since organisms often use some information_Greene 1987; Danchin et al. 2004; Dall et al. 2005; Avarguès-Weber, Dawson \& Chittka 2013) but rarely have perfect information. Significant progress in understanding dispersal itself will require specific attention to biologically plausible mechanisms for gathering information (Schmidt et al. 2010). Recent models have investigated how information on local population density affects dispersal (Travis, Murrell \& Dytham 1999; Cadet et al. 2003; Ronce 2007; Enfjäll \& Leimar 2009; Hovestadt, Kubisch \& Poethke 2010; Bocedi, Heinonen \& Travis 2012), but it is becoming increasingly clear that organisms use a variety of information sources (Ronce et al. 2001;

Danchin et al. 2004; Bonnie \& Earley 2007; Clobert et al. 2009; Schmidt et al. 2010) that might inform them about the presence or content of other populations in the landscape without direct measurement. We call these forms of information that do not result from direct sampling of the environment “indirect information” (Doligez, Danchin \& Clobert 2002; Danchin et al. 2004; Blanchet et al. 2010). For example, tourists in Paris are easily identified by the fact that they are using maps (unlike Parisians) and this might suggests_to Parisians that there is indeed a habitable world outside of Paris. These more 'indirect' sources of information derived from the observation of conspecifics are more controversial because they less accurately predict fitness in any given patch (Schmidt et al. 2010). However, indirect information carries a distinct advantage 
58 of providing some information about other patches without requiring costly exploration of other

59 sites.

60 A few recent empirical examples in birds, lizards, and other organisms now suggest that

61 indirect social information is accessible and used by individuals in making dispersal decisions

62 (Doligez et al. 2002; Cote \& Clobert 2007a; Chaine et al. 2010; De Meester \& Bonte 2010). For

63 example, in the common lizard (Zootoca vivipara), juveniles use a number of direct and indirect

64 sources of information to make dispersal decisions (Clobert, Massot \& Le Galliard 2012b).

65 Juveniles gain direct information by sampling the density of their patch (Le Galliard, Ferriere \&

66 Clobert 2003) and regarding kin competition (especially mother-offspring competition; Léna et

67 al. 1998; De Fraipont et al. 2000). However, juveniles also gain indirect information based on the

68 arrival of new immigrants (Cote \& Clobert 2007b; Cote, Boudsocq \& Clobert 2008; Cote \&

Clobert 2012) and the failure of emigrants to find a new populations (Cote \& Clobert 2007a).-

Likewise, some spider species, use both direct sampling of information on density, habitat

quality, and wind direction (Bonte et al. 2003a; Bonte et al. 2003b; Bonte, Bossuyt \& Lens 2007;

Bonte, Van Belle \& Maelfait 2007; De Meester \& Bonte 2010) as well as indirect information

such as the number of other individuals dispersing (De Meester \& Bonte 2010). Yet it remains

unclear how prevalent this behavioruse of indirect information in dispersal might be across

species. Widespread use of indirect information would dramatically alter our understanding of

77 well as applied conservation.

78 Using a theoretical model, we show that simple rules for the use of indirect social

79 information in dispersal decisions can evolve under a broad range of conditions and therefore

80 might be quite common in nature. We investigated the evolution of information use prior to 
81 dispersal using a simple metapopulation model in which we allowed information use in dispersal

82 to evolve. We were primarily interested in whether the use of indirect information provided by

83 immigrants could evolve, and if so, could it evolve in competition with direct information about

84 local density.

THE MODEL

87

We constructed an individual-based model of informed dispersal behavior, based on

information about the local density and/or the number of immigrants, while simplifying the

landscape and genetic features of the system. This individual-based model follows a

female-based life cycle with two age-classes (individuals in the population are juveniles from

birth until age 1, subadults from age 1 to 2, and adults after age 2) and age-specific survival and

fecundity (Caswell 2001, and see Fig. 1). Only juveniles dispersed and this dispersal depended

on baseline uninformed dispersal that alleviates kin competition (U) and informed dispersal (D

and I) as described below. Our basic model used a 'fast' life history roughly equivalent to a small

lizard or passerine life cycle (survival: $\underline{s}_{0}=0.2, s_{1}=0.35, \underline{s}_{2}=0.5$; fecundity: $\mathrm{f}_{1}=7, \mathrm{f}_{2}=7$, see

Schoener et al. 2003; Legendre et al. 2008). In each patch, discrete time structured population

dynamics were modeled tsing a two age class life cycle with age-specific demographic parameters (Fig. 1). Our initial model used a 'fast' life history roughly equivalent to a small lizard or passerine life cycle (survival: $s_{\theta}=0.2, s_{1}=0.35, s_{z}=0.5$; fecundity: $f_{4}=7, f_{z}=7$ ). Juveniles

101

102 were given the opportunity to disperse to other patches prior to the subsequent reproductive episode if they survived their first year. All patches were equally connected (leading to lower kin

103 competition) and population size was limited at reproduction by the maximum patch carrying 
104 capacity which was the same for all patches $(K=100)$. This configuration leads to very stable

105 populations with low levels of demographic stochasticity, lower kin competition, and very small

106 benefits of dispersal (populations are all similarly near $K$ ) essentially creating a conservative

107 scenario for the evolution of informed dispersal. Subsequent simulations introduced increased

108 stochasticity to explore the benefits of information use under other scenarios (see SOM).

109 The simulation was in discrete time. Individuals were described by their age, the values of their

110 adaptive traits (see below), their patch of residence, their dispersal status, the strategy they

111 played if they dispersed, and the probability of dispersal. At each time step, the following

112 operations are performed in sequential order for all individuals in the metapopulation: Survival;

113 Reproduction and mutation; Dispersal.Basic Loop

$114 \quad$ The simulation is in discrete time. Individuals are described by their age, the values of

115 their adaptive traits, their patch of residence, their dispersal status, the strategy they played if

116 they dispersed, the probability of dispersal, and the cost of dispersal.

117 At each time step, the following operations are performed:

$118 \mid$ Survival

119 \& Reproduction and mutation

$120 \mid$ Dispersal

121 Increase time step

122 1) Survival: Surviving juveniles become subadults, surviving subadults become adults, and

123 adults have a constant survival rate. Survival was determined by a Bernoulli draw according to

124 the age-specific survival. 
125 2) Reproduction: Subadults and adults reproduced according to their age-specific reproductive

126 rate. Fecundity was drawn using a Poisson distribution, but limited by the patch carrying

127 capacity.

128 3) Mutation: Offspring inherited their parental dispersal genotype (coefficients of the dispersal

129 functions, $D$ and $I$, described below) with a 0.02 probability of mutation. The degree of mutation

130 on $D, I$, and $U$ in later models (see additional results in SOM) was set by a random draw from a

131 Gaussian distribution with a standard deviation of 0.02 . These mutations have the effect of

132 causing a slight alteration in how intensely the dispersal decision will respond to a given set of

133 local cues (local density and number of immigrants).

134 4) Dispersal: Offspring were given the opportunity to disperse according to their dispersal

135 strategy (i.e. genotype), and current conditions that informed their dispersal strategy. Specific

136 dispersal strategy functions are described below. Since the first individuals to disperse at a given

137 time step would only have access to local density information (no immigrants possible since

138 nobody has yet dispersed), we randomized at each time step the order in which individuals were

139 selected for dispersal across the whole metapopulation. We chose to model dispersal behavior on

140 current density and immigrant number rather that everyone using the same values from the

141 previous time step because it reflects a much more biologically realistic mechanism for

142 information use in dispersal as newborns gather information about their surroundings(Matthysen

143 2012. If an individual juvenile dispersed, it could die during dispersal according to the costs of

144 dispersal (varied in simulations from 0-0.1 in additional results; see SOM) or arrive at a new

145 destination patch. This cost of dispersal modified the juvenile survival rate $\left(\mathrm{s}_{0} \times(1\right.$-cost $\left.)\right)$.

146 Juveniles who survived dispersal, were randomly assigned a new patch, excluding their natal 
147 patch, and were then counted as an immigrant for that new patch. All patches were equally

148 eonnected.

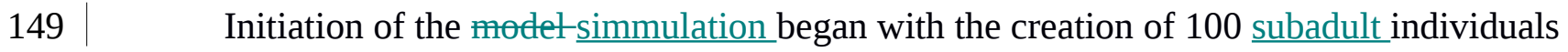

150 with identical genotype in a single patch. Individuals then reproduced and their offspring who

151 dispersed began to colonize the patches.

152

153 Dispersal Functions

$154 \quad$ We modeled two forms of information use that could influence dispersal: 1) a measures

155 of the local density which are known to provide a benefit to dispersal behavior (Cadet et al.

156 2003) and 2) a measures of the number of immigrants entering a patch (Cote \& Clobert 2007a).

157 Local density directly influences reproductive success whereas the number of arriving

158 immigrants indicates that other populations are attainable and may provide some information

159 about overall metapopulation density. The influence of local density and immigrant-borne

160 information on dispersal behavior $\left(B_{x}\right)$ were modeled as:

161

$162 \quad$ Density-dependent: $\quad B_{D}=D \frac{n_{i}}{K_{i}}-2$

163

$164 \quad$ Immigrant-dependent : $\quad B_{I}=\mathfrak{I}_{i}-2$

165

$166 \mid$ where $n_{i}$ is the number of individuals in patch $i, K_{i}=K$ is the patch carrying capacity $\underline{K}$, and $M_{i}$ is

167 the number of immigrants entering the patch. The coefficients ( $D$ and $I$ ) influenced the intensity

168 of these behaviors and each was free to evolve independently of the others. Immigrant-dependent

169 dispersal only occurred if immigrants were present (i.e. if $M_{i}>0$ ). Fixed intercepts(-2) were 
170 included to set a lower limit to dispersal via each form of information use at $12 \%$. This intercept

171 allowed dispersal to evolve more rapidly without having an impact on the evolved dispersal rate

172 which was always significantly higher (see SOM, Fig. S8). We assumed haploid genetics and

173 clonal reproduction with mutation in 'genes' for the coefficients ( $D$ and $I$ ) that affect each

174 informed-dispersal strategy as described above. These behaviors were then used to determine the

175 probability of dispersal, $d(x)$, associated with density $\left(d_{\mathrm{D}}\right)$ and immigrant $\left(d_{\mathrm{I}}\right)$ information sources

176 using the following function:

$$
d(x)=\frac{1}{1+\exp (-x)}
$$

where $x$ is the influence of each form of information described by equations 1 and $2\left(x=B_{D}\right.$ or

$\left.\underline{B}_{I}\right)$. This function allowed us to convert the biologically meaningful relationships described in equations 1 and 2 to probabilities of dispersal $d_{\mathrm{D}}$ and $d_{\mathrm{I}}$ respectively.

dispersal already occurs), we also included a fixed parameter for baseline uninformed dispersal

$\left(d_{\mathrm{U}}=0.1\right)$. Uninformed dispersal should alleviate kin competition and increased values when

allowed to evolve would be favored when kin competition is higher. Dispersal was always drawn

for uninformed dispersal first $\left(d_{\underline{U}}\right)$ and then for informed dispersal $\left(d_{D}\right.$ or $\left.d_{I}\right)$, that always

өecurred prior to the use of either density or immigrant information sources.Removal of this

baseline dispersal prevents the evolution of immigrant-dependent dispersal when alone (I-only

models) since there were no immigrants, but it had little influence on the evolution of

191

density-dependent dispersal (D-only models) or both density and immigrant-dependent dispersal

192 when both were present (D\&I models; Fig. S9). Allowing this baseline uninformed dispersal (U) 
193

194

195

196

197

198

199

200

201

202

203

204

205

206

207

208

209

210

211

212

213

214

to evolve had little effect on the evolution of informed dispersal (D-only, I-only, or D\&I; Fig.

S10). Dispersers were randomly assigned to a new pateh. Dispersers were subsequently counted as immigrants that could influence the behavior of other juveniles during a given dispersat episode in models ineluding immigrant-dependent dispersal. Individual juveniles were selected at random aeross the metapopulation to take their dispersal decisions. Indeed, those chosen early were much less likely to have seen immigrants than those chosen to make their dispersal decisiontater.

We constructed alternative models of information use to examine the independent effects of density (D-only) and-or immigrants (I-only) on dispersal as well as their joint co-evolutionary dynamics when individuals could use both forms of information simultaneously (D\&I). In models including both density- and immigrant-dependent information (D\&I), all individuals were capable of using both sources of information and the sum of the two sources of information determined the dispersal probability. This assumption matches empirical findings that individuals use multiple sources of information in decision making (Le Galliard et al. 2003; Cote \& Clobert 2007b; Cote et al. 2008; Clobert et al. 2009; Clobert et al. 2012b; Cote \& Clobert 2012;

Matthysen 2012). In the case of simultaneous models, if $d_{B}+d_{t}>1$, then the individual dispersed dispersed, otherwise it disperset with probability $\left(d_{\mathrm{D}}+d_{\underline{\perp}}\right.$ if $d_{\underline{D}}+d_{\underline{I}}<1$, and always dispersed if $\underline{d_{D}}+d_{\underline{I}}>1$ ). The information source used to $\in \underline{W e}$ calculated the 'realized' informed dispersal rates attributed to each information sourcein this case was determined by a random draw using the relative dispersal probability of each information source $\left(d_{\mathrm{D}}\right.$ or $\left.d_{\mathrm{I}}\right)$. The probabilities $d_{\mathrm{D}}$ and $d_{\mathrm{I}}$ represent the incentive of an individual to disperse according to density or immigrant information, and are not the realized dispersal rates associated with each strategy. These realized 


\section{5}

216

217

218

219

220

221

222

223

224

225

226

227

228

229

230

231

232

233

234

Results

235

236 Evolution of Information Use: single source of information

strategy divided by the total number of individuals in the metapopulation.

supplemental materials (see SOM). immigrant information use strategy function.
RESULTS

dispersal rates were computed as the total number of individuals dispersing according to each

We determined the probability that informed dispersal evolved and the dispersal rate

associated with information use using Monte Carlo simulations of 100 trajectories over $1.5 \times 10^{6}$

time steps for each set of parameters and each model case. Because all individuals were capable

of information use from one or two sources, then all values of the evolved coefficient potentially

existed in the population unless the entire metapopulation went extinct. Therefore, we

determined that 'evolution' of an informed dispersal strategy had occurred if the evolved

coefficient was greater than 0 more often than by chance across simulations since drift should

lead to negative coefficients as often as positive ones. This approach gives similar results to

quantify evolution if it increases above an estimate of random drift as presented in the

Our initial model exploration focused on the use of density and immigrant sources of

information and the coevolution of both forms when together. Subsequent models (see SOM) explored the effects of variation in the costs of dispersat,life history, carrying capacity, patch number, environmental stochasticity, the costs of dispersal (Bonte et al. 2012), variation in baseline dispersal $\left(d_{\mathrm{U}}\right)$, the order in which different sources of information are used, and the 
We found that informed dispersal could evolve and drive dispersal behavior and

238

239

240

241

242

243

244

245

246

247

248

249

250

251

252

253

254

255

256

257

258

259

metapopulation dynamics under a broad range of contexts. Consistent with other models (Travis

et al. 1999; Ronce 2007), we found that density dependent dispersal evolves when it is the only

source of information (Fig. 2a, 3). Here we show that the arrival of immigrants also provides

useful information that can drive dispersal behavior (Fig. 2b, 3). Indeed, information-dependent

dispersal coefficients (D and I) were significantly biased towards positive values in contrast to

expectations from drift which should lead to an equal probability of positive and negative values

(Sign test: D-only: 97/100 positive trials, $\mathrm{P}<0.0001$; I-only: 99/100 positive trials, $\mathrm{P}<0.0001$ ).

Both density and immigrant dependent dispersal evolved even when each was in competition

with uninformed dispersal (fixed $d_{\mathrm{U}}=10 \%$ and when $\mathrm{U}$ was allowed to evolve; see SOM and

Fig. S9, S10a) and lead to increased dispersal from that source of information (Fig. 2a,b) despite

a highly stable and homogenous landscape. Dispersal reaction norms due to information use

illustrate this nicely: local density and immigrant number influence dispersal (Fig. 4a and b

respectively) at equilibrium compared to a flat, fixed dispersal rate of uninformed dispersal.

Density-dependent dispersal shows a steady increase in dispersal as local density rises (Fig. 4a).

In contrast, immigrant-dependent dispersal shows a rapid increase in dispersal with the first few immigrants and then quickly asymptotes at high levels of dispersal (Fig. 4b).

For informed dispersal to evolve there must be some benefit to these strategies.

Individuals benefit from dispersal when they find a new population with a lower density given

that fitness is density-dependent. We compared the density of the new destination patch and an

individual's original patch right before reproduction to estimate the benefit of dispersal to that

individual. Informed dispersal led to discovery of a less dense patch than the population of origin

on average. Both density and immigrant information seemed to present very similar advantages 
260 early in the evolutionary process (Fig. S5a,b and Fig. 5a). However, the benefit of informed

261 dispersal was extremely slight (0.5-0.02\%) since the landscape was largely homogenous and

262 most populations were very close to their carrying capacity at all times. Environmental

263 stochasticity augmented spatial heterogeneity in patch density and led to a larger benefit during

264 the evolution of informed dispersal (Fig. 5a; Fig. S5; see also McPeek \& Holt 1992; Travis \&

265 Dytham 1999).

266

267 Evolution of Information Use: multiple sources of information

268 Coexistence of density and immigrant dependent dispersal occurred often in our model

269 when both forms of information use were possible (48\% of simulations for model D\&I; Fig. 2c

270 and 3). Information-dependent dispersal coefficients for both behaviors (D and I) were again

271 significantly biased towards positive values overall in contrast to expectations from drift (Sign

272 test for D\&I model: D: 65/100 positive trials, $\mathrm{P}=0.035$; I: 82/100 positive trials, $\mathrm{P}<0.0001$ ).

273 Reaction norms of density- and immigrant-dependent dispersal both show increases with density

274 or immigrant number respectively and rise well above background levels of uninformed dispersal

275 (Fig. 4c,d). If we contrast these reaction norms to the reaction norms that evolve when only one

276 form of information use is possible, we see that the slope of density dependent dispersal

277 decreases considerably (Fig. 4a vs. c) whereas the shape of the immigrant-dependent dispersal

278 curve changes only slightly (Fig. $4 \mathrm{~b}$ vs. d; dispersal above $98 \%$ at 3 vs. 5 immigrants

279 respectively). Optimal levels of density-dependent dispersal therefore shift considerably when

280 another source of information affects dispersal. In contrast, immigrant-dependent information

281 has large effects on dispersal with the arrival of the first few immigrants and this trigger does not

282 change much when other sources of information are available. 
$32 \%$ and $17 \%$ for density and immigrant dependent dispersal respectively), coexistence remained

high when in competition with a second source of information (D\&I) relative to models where just one strategy was possible (D-only or I-only; Fig. 3). Joint evolution of both information use behaviors occurred even in competition with uninformed baseline dispersal (see SOM, Fig. S9, 288 S10, S11).

290 information were used together relative to using just one source of information. This benefit was 291 most apparent when demographic stochasticity increased. Lower population carrying capacities 292 raised the risk of extinction due to increased demographic stochasticity, and for a narrow window 293 of carrying capacities the use of two sources of information helped reduce the risk of extinction 294 for the metapopulation as a whole by $20-40 \%$ relative to use of just one source of information 295 (Fig. 5d). At slightly lower carrying capacities, when metapopulation extinction always occurred, 296 the use of two different sources of information lead to longer persistence (200-10000 time steps 297 or roughly 100-5000 generations; Fig. S3) of the metapopulation than if just one source of 298 information was used. An increase in the frequency of environmental stochasticity lead to higher 299 metapopulation extinction, and the risk of extinction was lower when one or more sources of 300 information was available (D-only or I-only or D\&I) compared to uninformed dispersal only 301 (U-only) (Fig. 5c). 
Our results show that informed dispersal evolves under a broad array of contexts and that both density and indirect immigrant-dependent information sources evolve and can coexist. The

307 frequent evolution of informed dispersal in the very conservative setup examined here (e.g.

308 stable metapopulation) suggests that use of a variety of information sources, including indirect

309 measures of the metapopulation landscape, could be common in nature. Indeed, direct

310 information use in dispersal decisions is widespread (Ims \& Hjermann 2001; Matthysen 2005;

311 Ronce 2007; Clobert et al. 2009; Schmidt et al. 2010) and the few empirical investigations of

312 indirect information use that we are aware of have found evidence for it despite a broad

313 taxonomic range. For example, common lizards modify their dispersal behavior in response to

314 immigrants who appear to provide information about the density of their natal population (Cote

315 \& Clobert 2007a). Likewise, our recent work in Tetrahymena ciliates shows that residents alter

316 their dispersal rate when arriving immigrants come from populations that differ in density or

317 social structure. In both of these empirical examples, immigrants carry more information (e.g.

318 population density) than we included in our model. This additional information should serve to

319 increase the fitness benefits of immigrant-dependent dispersal suggesting that we have probably

320 underestimated the likelihood that it evolves.

321 For use of both information sources to evolve, there must be benefits to adjust behavior

322 using two sources of information rather than a single source. Benefits of density-dependent

323 dispersal are well known since movement out of high density patches should have direct fitness

324 benefits when reproduction is density dependent (Travis et al. 1999; Matthysen 2005; Cote et al.

325 2008). Our results demonstrate that even under very conservative conditions, immigrant

326 dependent dispersal also presents a benefit and evolves. Likewise, coexistence of density- and

327 immigrant-dependent dispersal even under the stable meta-population structure that we modeled 
328 suggests that these behaviors can evolve and coexist frequently even when the benefits of each

329 behavior are low. Coexistence also implies that neither source of information carries benefits that

330 would cause competitive exclusion of the other information source. Using two sources of

331 information also provided additional benefits and could play an important role in metapopulation stability, especially as increased stochasticity creates larger inequalities in population densities.

The benefits of using multiple information sources (decreased extinction risk) that we measured

occurred for a small range of meta-population conditions (medium levels of stochasticity), but

they suggest an important advantage to informed dispersal under less stable conditions of most

real meta-populations. While the benefits we measured in our model were small in the relatively

homogenous landscape we constructed, conditions that more realistically imitate empirical

landscapes should confer much larger benefits to this behavior.

information content of density and immigrant number were not sufficiently different or if one information source was superior to the other (Enfjäll \& Leimar 2009; Hovestadt et al. 2010;

Schmidt et al. 2010; Bocedi et al. 2012). Immigrant arrival might be related to the overall density

343 of the metapopulation since populations that have more individuals will generate more 
$351 \mid$ of information. Yet weMore frequently, we found coexistence of information use through both

352 density and immigrant information. This suggests that each source of information is not fully

353 redundant and that one source of information is not necessarily superior to the other. This

354 equivalency of information can serve as an advantage under some contexts (e.g. when

355 stochasticity is high; Fig. 5 and S3) and would be especially useful where the costs of

356 information use from one source might constrain dispersal below an optimal level (Bocedi et al.

357 2012). Likewise, if immigrants also carry additional information about their populations (Cote \&

358 Clobert 2007a) or help orient dispersers towards certain populations, then we could expect the

359 benefits of indirect information use to be even more advantageous.

The potential prevalence of informed dispersal has a number of important implications

361 for both fundamental and applied ecology. In basic ecological research, the use of information

362 has recently been explored in terms of density dependent dispersal, and this simple behavior

363 greatly effects how movement influences population persistence (Ims \& Hjermann 2001; Cadet

364 et al. 2003; Matthysen 2005). Earlier models of 'informed' dispersal—such as 'ideal free

365 distribution' models_-generally assumed perfect knowledge of the landscape (Abrahams 1986;

366 Gray \& Kennedy 1994; Holt \& Barfield 2001) which presumably was acquired through

367 prospecting that carried low costs. Low cost prospecting might work when patches are close (e.g.

368 foraging patches), but is less realistic when habitat patches are more distant. The use of indirect

369 information, such as the arrival of immigrants, could provide another mechanism by which the

370 ideal free distribution is achieved (Baguette, Clobert \& Schtickzelle 2010). If immigrant arrival

371 is linked to overall metapopulation density and if immigrants carry additional information about

372 the quality of those habitats as suggested in empirical examples (Cote \& Clobert 2007a), then we

373 might approach an ideal free distribution through use of indirect information transfer across the 
374 landscape. Deviation from ideal free models might then in part reflect the quality or reliability of

375 that indirect information transfer (see also Abrahams 1986; Gray \& Kennedy 1994; Chaine \&

376 Clobert 2012). Most likely, individuals use a number of sources of information on local

377 conditions, direct prospecting of nearby patches, and indirect measures of the landscape such as

378 immigrant-borne information (Clobert et al. 2009). If this form of information use is prevalent,

379 then we must shift our view of dispersal from largely random movement among populations to

380 much more targeted and informed movement patterns that approach ideal-free expectations.

381 Connectivity and dispersal are crucial aspects of population persistence, yet studies of

382 dispersal and metapopulation dynamics usually ignore the important role that information

383 transfer across the landscape might play in guiding subsequent dispersal decisions. Applied

384 management or conservation efforts to increase connectivity or gene flow might be greatly

385 hampered if we do not also introduce the indirect cues that influence dispersal. Indeed, the highly

386 variable success of artificial corridors (Gilbert-Norton et al. 2010) could in part be caused by the

387 lack of indirect information since immigrants will be rare when a new corridor is first

388 constructed (see also Le Galliard et al. 2003). More generally, conservation efforts could be

389 greatly aided by modifying natural dispersal through the manipulation of information that is

390 accessible to residents rather than by costly alterations of the landscape between habitat patches

391 (Chaine \& Clobert 2012). As we show here, access to multiple sources of information may better

392 mitigate extinction risk in highly stochastic environments compared to situations where little

393 information exists. Broader inclusion of how information is used in dispersal should provide us

394 with new tools for conservation and fundamentally modify our approach to conservation ecology

395 and the management of populations in peril. 
of information use into this field. We found the evolution of both forms of informed dispersal

despite potentially large differences in the quality of information gleaned from each source.

Whereas local density directly affects fitness, immigrant arrival at best gives some indication of surrounding population sizes when density dependent dispersal exists and at worst simply provides evidence that other populations exist. Coexistence of the two sources of information suggests that the quality of information may be somewhat less important than the presence of that information. In support of this notion, models of indirect information use based on immigrant presence rather than immigrant number show very similar results (Fig. S12). This result is empirically supported by the fact that dispersal in the common lizard was found to be sensitive to the presence and not to the quantity of immigrants (Cote \& Clobert 2007a). Similarly, recent models of density dependent information use suggest that the precision of 408 information provides diminishing returns and high quality information is not optimal when it 409 also incurs elevated costs associated with gathering additional precision (Bocedi et al. 2012).

410 Both of these investigations adopt very simple dispersal contexts and yet both show that

411 information use in dispersal evolves quite readily and should be common in nature. More

412 generally, the passive information transfer across the landscape that evolves in our models could

413 be an important first evolutionary step that allows more active information transfer and

414 communication to evolve both within populations and across landscapes. 
418 We thank O. Ronce and B. Lyon for comments on an early draft and discussions on this topic and

419

420

421

422

423

424

425

426

427 428

429

430

431

432 433

434 435 436

437 438 439 440

anonymous reviewers for additional comments. J.C. was supported by French ANR BLANC grants DIAME and INDHET, and program Biodiversa TenLamas. J.C. and A.S.C. received support from the CNRS and ANR-INFO-EVO-ECO, and A.S.C received support from ANR-JCJC NetSelect. This work is part of the Laboratoire d'Excellence (LABEX) entitled TULIP (ANR-10-LABX-41).

\section{REFERENCES}

Abrahams, M. V. 1986. Patch choice under perceptual constraints: a cause for departures from an ideal free distribution. Behavioral Ecology and Sociobiology, 19, 409-415.

Avarguès-Weber, A., Dawson, E. H. \& Chittka, L. 2013. Mechanisms of social learning across species boundaries. Journal of Zoology, earlyview.

Baguette, M., Clobert, J. \& Schtickzelle, N. 2010. Metapopulation dynamics of the bog fritillary butterfly: experimental changes in habitat quality induced negative density-dependent dispersal. Ecography, 170-176.

Blanchet, S., Clobert, J. \& Danchin, É. 2010. The role of public information in ecology and conservation : an emphasis on inadvertent social information. Annals of the New York Academy of Sciences, 1195, 149-168.

Bocedi, G., Heinonen, J. \& Travis, J. M. J. 2012. Uncertainty and the role of information acquisition in the evolution of context-dependent emigration. American Naturalist, 179, 606-620. Bonnie, K. E. \& Earley, R. L. 2007. Expanding the scope for social information use. Animal Behaviour, 74, 171-181. 
441 Bonte, D., Bossuyt, B. \& Lens, L. 2007. Aerial dispersal plasticity under different wind

442 velocities in a salt marsh wolf spider. Behavioral Ecology, 18, 438-443.

443 Bonte, D., Lens, L., Maelfait, J.-P., Hoffmann, M. \& Kuijken, E. 2003a. Patch quality and 444 connectivity influence spatial dynamics in a dune wolfspider. Oecologia, 135, 227-233.

445 Bonte, D., Van Belle, S. \& Maelfait, J.-P. 2007. Maternal care and reproductive state-dependent 446 mobility determine natal dispersal in a wolf spider. Animal Behaviour, 74, 63-69.

447 Bonte, D., Van Dyck, H., Bullock, J. M., Coulon, A., Delgado, M., Gibbs, M., Lehouck, V., 448 Matthysen, E., Mustin, K., Saastamoinen, M., Schtickzelle, N., Stevens, V. M., Vandewoestijne, 449 S., Baguette, M., Barton, K., Benton, T. G., Chaput-Bardy, A., Clobert, J., Dytham, C., 450 Hovestadt, T., Meier, C. M., Palmer, S. C. F., Turlure, C. \& Travis, J. M. J. 2012. Costs of 451 dispersal. Biological Reviews, 87, 290-312.

452 Bonte, D., Vandenbroecke, N., Lens, L. \& Maelfait, J.-P. 2003b. Low propensity for aerial 453 dispersal in specialist spiders from fragmented landscapes. Proceedings of the Royal Society of 454 London. Series B: Biological Sciences, 270, 1601-1607.

455 Bowler, D. E. \& Benton, T. G. 2005. Causes and consequences of animal dispersal strategies:

456 relating individual behaviour to spatial dynamics. Biological Reviews, 80, 205-225.

457 Cadet, C., Régis Ferrière, Johan A. J. Metz \& van Baalen, M. 2003. The Evolution of Dispersal 458 under Demographic Stochasticity. American Naturalist, 162, 427-441.

459 Caswell, H. 2001. Matrix population models: Construction, analysis and interpretation.

460 Sunderland, MA: Sinauer Associates.

461 Chaine, A. S. \& Clobert, J. 2012. Dispersal. In: Behavioral responses to a changing world (Ed.

462 by U. Candolin \& B. B. M. Wong), pp. 63-79. Oxford: Oxford University Press. 
463 Chaine, A. S., Schtickzelle, N., Polard, T., Huet, M. \& Clobert, J. 2010. Kin-based recognition 464 and social aggregation in a ciliate. Evolution, 64, 1290-1300.

465 Clobert, C., Baguette, M., Benton, T. G. \& Bullock, J. M. 2012a. Disersal ecology and evolution. 466 Oxford: Oxford University Press.

467 Clobert, J., Danchin, E., Dhondt, A. A. \& Nichols, J. D. 2001. Dispersal. New York: Oxford 468 Univ Press.

469 Clobert, J., Galliard, J.-F. L., Cote, J., Meylan, S. \& Massot, M. 2009. Informed dispersal, 470 heterogeneity in animal dispersal syndromes and the dynamics of spatially structured 471 populations. Ecology Letters, 12, 197-209.

472 Clobert, J., Massot, M. \& Le Galliard, J.-F. 2012b. Multi-determinism in natal dispersal: the 473 common lizard as a model system. In: Dispersal Ecology and Evolution (Ed. by J. Clobert, M.

474 Baguette, T. G. Benton \& J. M. Bullock), pp. 29-37. Oxford, UK: Oxford University Press.

475 Cote, J., Boudsocq, S. \& Clobert, J. 2008. Density, social information, and space use in the 476 common lizard (Lacerta vivipara). Behavioral Ecology, 19, 163-168.

477 Cote, J. \& Clobert, J. 2007a. Social information and emigration: lessons from immigrants.

478 Ecology Letters, 10, 411-417.

479 Cote, J. \& Clobert, J. 2007b. Social personalities influence natal dispersal in a lizard.

480 Proceedings of the Royal Society B: Biological Sciences, 274, 383-390.

481 Cote, J. \& Clobert, J. 2012. Dispersal syndromes in the common lizard: personality traits, 482 information use and context-dependent dispersal decisions. In: Dispersal Ecology and Evolution 483 (Ed. by J. Clobert, M. Baguette, T. G. Benton \& J. M. Bullock), pp. 152-158. Oxford, UK: 484 Oxford University Press. 
485 Dall, S. R. X., Giraldeau, L.-A., Olsson, O., McNamara, J. M. \& Stephens, D. W. 2005.

486 Information and its use by animals in evolutionary ecology. Trends in Ecology and Evolution, 20, $487 \quad 187-193$.

488 Danchin, E., Giraldeau, L.-A., Valone, T. J. \& Wagner, R. H. 2004. Public Information: From 489 Nosy Neighbors to Cultural Evolution. Science, 305, 487-491.

490 De Fraipont, M., Clobert, J., John, H. \& Alder, S. 2000. Increased pre-natal maternal 491 corticosterone promotes philopatry of offspring in common lizards Lacerta vivipara. Journal of 492 Animal Ecology, 69, 404-413.

493 De Meester, N. \& Bonte, D. 2010. Information use and density-dependent emigration in an 494 agrobiont spider. Behavioral Ecology, 21, 992-998.

495 Doligez, B., Danchin, E. \& Clobert, J. 2002. Public information and breeding habitat selection in 496 a wild bird population. Science, 297, 1168-1170.

497 Enfjäll, K. \& Leimar, O. 2009. The evolution of dispersal - the importance of information about 498 population density and habitat characteristics. Oikos, 118, 291-299.

499 Gilbert-Norton, L., Wilson, R., Stevens, J. R. \& Beard, K. H. 2010. A Meta-Analytic Review of 500 Corridor Effectiveness. Conservation Biology, 24, 660-668.

501 Gray, R. D. \& Kennedy, M. 1994. Perceptual constraints on optimal foraging: a reason for 502 departures from the ideal free distribution? Animal Behaviour, 47, 469-471.

503 Greene, E. 1987. Individuals in an osprey colony discriminate between high and low quality 504 information. Nature, 329, 239-241.

505 Hanski, I. A. \& Gaggiotti, O. E. 2004. Ecology, Genetics and Evolution of Metapopulations. 506 Amsterdam: Academic Press. 
507 Holt, R. D. \& Barfield, M. 2001. On the relationship between the ideal free distribution and the 508 evolution of dispersal. In: Dispersal (Ed. by J. Clobert, E. Danchin, A. A. Dhondt \& J. D.

509 Nichols), pp. 83-95. Oxford, UK: Oxford University Press.

510 Hovestadt, T., Kubisch, A. \& Poethke, H.-J. 2010. Information processing in models for

511 density-dependent emigration: A comparison. Ecological Modelling, 221, 405-410.

512 Ims, R. A. \& Hjermann, D. 2001. Condition dependent dispersal. In: Dispersal (Ed. by J.

513 Clobert, E. Danchin, A. Dhondt \& J. D. Nichols), pp. 203-216. New York: Oxford University

514 Press.

515 Le Galliard, J. F., Ferriere, R. \& Clobert, J. 2003. Mother-offspring interactions affect natal

516 dispersal in a lizard. Proceedings of the Royal Society B, 270, 1163-1169.

517 Legendre, S., Schoener, T. W., Clobert, J. \& Spiller, D. A. 2008. How is extinction risk related to

518 population-size variability over time? A family of models for species with repeated extinction

519 and immigration. American Naturalist, 172, 282-298.

520 Léna, J.-P., Clobert, J., de Fraipont, M., Lecomte, J. \& Guyot, G. 1998. The relative influence of

521 density and kinship on dispersal in the common lizard. Behavioral Ecology, 9, 500-507.

522 Matthysen, E. 2005. Density-dependent dispersal in birds and mammals. Ecography, 28, 523 403-416.

524 Matthysen, E. 2012. Multicausality of dispersal In: Dispersal Ecology and Evolution (Ed. by J.

525 Clobert, M. Baguette, T. G. Benton \& J. M. Bullock), pp. 3-12. Oxford, UK: Oxford University 526 Press.

527 McPeek, M. A. \& Holt, R. D. 1992. The evolution of dispersal in spatially and temporally 528 varying environments. American Naturalist, 140, 1010-1027. 
529 Nathan, R., Getz, W. M., Revilla, E., Holyoak, M., Kadmon, R., Saltz, D. \& Smouse, P. E. 2008.

530 A movement ecology paradigm for unifying organismal movement research. Proceedings of the

531 National Academy of Sciences, USA, 105, 19052-19059.

532 Ronce, O. 2007. How Does It Feel to Be Like a Rolling Stone? Ten Questions About Dispersal

533 Evolution. Annual Review of Ecology, Evolution, and Systematics, 38, 231-253.

534 Ronce, O., Olivieri, I., Clobert, J. \& Danchin, E. 2001. Perspectives on the study of dispersal

535 evolution. In: Dispersal (Ed. by J. Clobert, E. Danchin, A. Dhondt \& J. D. Nichols), pp.

536 341-357. New York: Oxford University Press.

537 Schmidt, K. A., Dall, S. R. X. \& Van Gils, J. A. 2010. The ecology of information: an overview

538 on the ecological significance of making informed decisions. Oikos, 119, 304-316.

539 Schoener, T. W., Clobert, J., Legendre, S. \& Spiller, D. A. 2003. Life-history models of

540 extinction: A test with island spiders. American Naturalist, 162, 558-573.

541 Travis, J. M. J. \& Dytham, C. 1999. Habitat persistence, habitat availability and the evolution of

542 dispersal. Proceedings of the Royal Society of London. Series B: Biological Sciences, 266,

$543 \quad 723-728$.

544 Travis, J. M. J., Murrell, D. J. \& Dytham, C. 1999. The evolution of density-dependent dispersal.

545 Proceedings of the Royal Society of London. Series B: Biological Sciences, 266, 1837-1842. 
1 Alexis S. Chaine ${ }^{1}$, Stéphane Legendre ${ }^{2}$, Jean Clobert ${ }^{1}$

2

3 'Station d'Ecologie Expérimentale du CNRS à Moulis, USR 2936, 2 route du CNRS, 09200

4 Moulis, France

$5 \quad{ }^{2}$ Laboratoire Ecologie \& Evolution, UMR7625, Ecole Normale Supérieure, 46 rue d'Ulm, 75230

6 Paris Cedex 05, France

7

8 Corresponding Author: alexis.chaine@ecoex-moulis.cnrs.fr;

9 Tel: +33561040378; Fax: +33561960851

10 Jean Clobert: jean.clobert@ecoex-moulis.cnrs.fr

11 Stéphane Legendre: legendre@biologie.ens.fr

12 
MULTIPLY-INFORMED DISPERSAL

\section{INTRODUCTION}

Dispersal is a key component of many ecological and evolutionary processes ranging

from population dynamics to local adaptation and has been the focus of extensive empirical and

theoretical investigation (Clobert et al. 2001; Ronce 2007; Nathan et al. 2008; Clobert et al.

2012a). The impact of dispersal on both population dynamics, movement across the landscape,

19 and local adaptation makes it a critical element of understanding how populations are affected by

20 landscape fragmentation and global warming (Chaine \& Clobert 2012). Dispersal has largely

21 been treated as a population level character even though dispersal decisions are fundamentally an

22 individual behavior that should benefit from knowledge of the landscape. Recent empirical

23 evidence suggests that information use in making dispersal decisions and navigating the

24 landscape plays an important role in patterns of dispersal (Bowler \& Benton 2005; Clobert et al.

25 2009; Schmidt, Dall \& Van Gils 2010). Information use would cause a shift in how we view

26 dispersal. Exchanges among populations would no longer represent a random subset of

27 genotypes and might affect local adaptation patterns (Blanchet, Clobert \& Danchin 2010).

28 Dispersers might not spread randomly across the landscape and some populations might receive

29 more or fewer immigrants due to dispersal cost (Bonte et al. 2012). In applied work, if we want

30 to encourage dispersal, we would need to make sure that the key information sources are

31 available or even manipulate information to get the desired level of dispersal (Blanchet et al.

32 2010; Chaine \& Clobert 2012). Yet our fundamental understanding of informed dispersal remains

33 limited (Clobert et al. 2009).

34 The use of information in dispersal decisions has received attention through a limited

35 range of possibilities despite potentially important effects on fitness (Ims \& Hjermann 2001; 
36 Ronce et al. 2001; Bowler \& Benton 2005; Clobert et al. 2009; Schmidt et al. 2010). Classical

37 ecological (metapopulation) and evolutionary (gene-flow) theory assumes constant dispersal

38 rates with random movement and no information use (Hanski \& Gaggiotti 2004). At the other

39 extreme, ideal free settlement models assume perfect knowledge of the entire landscape which

40 influences dispersal (Holt \& Barfield 2001). Both approaches are analytically tractable, but

41 biologically unrealistic since organisms often use some information (Greene 1987; Danchin et al.

42 2004; Dall et al. 2005; Avarguès-Weber, Dawson \& Chittka 2013) but rarely have perfect

43 information. Significant progress in understanding dispersal itself will require specific attention

44 to biologically plausible mechanisms for gathering information (Schmidt et al. 2010).

Recent models have investigated how information on local population density affects

dispersal (Travis, Murrell \& Dytham 1999; Cadet et al. 2003; Ronce 2007; Enfjäll \& Leimar

2009; Hovestadt, Kubisch \& Poethke 2010; Bocedi, Heinonen \& Travis 2012), but it is becoming increasingly clear that organisms use a variety of information sources (Ronce et al. 2001;

49 Danchin et al. 2004; Bonnie \& Earley 2007; Clobert et al. 2009; Schmidt et al. 2010) that might

50 inform them about the presence or content of other populations in the landscape without direct

51 measurement. We call these forms of information that do not result from direct sampling of the

52 environment “indirect information” (Doligez, Danchin \& Clobert 2002; Danchin et al. 2004;

53 Blanchet et al. 2010). For example, tourists in Paris are easily identified by the fact that they are

54 using maps (unlike Parisians) and this might suggest to Parisians that there is indeed a habitable

55 world outside of Paris. These more 'indirect' sources of information derived from the

56 observation of conspecifics are more controversial because they less accurately predict fitness in

57 any given patch (Schmidt et al. 2010). However, indirect information carries a distinct advantage 
MULTIPLY-INFORMED DISPERSAL

58 of providing some information about other patches without requiring costly exploration of other

59 sites.

60 A few recent empirical examples in birds, lizards, and other organisms now suggest that

61 indirect social information is accessible and used by individuals in making dispersal decisions

62 (Doligez et al. 2002; Cote \& Clobert 2007a; Chaine et al. 2010; De Meester \& Bonte 2010). For

63 example, in the common lizard (Zootoca vivipara), juveniles use a number of direct and indirect

64 sources of information to make dispersal decisions (Clobert, Massot \& Le Galliard 2012b).

65 Juveniles gain direct information by sampling the density of their patch (Le Galliard, Ferriere \&

66 Clobert 2003) and regarding kin competition (especially mother-offspring competition; Léna et

67 al. 1998; De Fraipont et al. 2000). However, juveniles also gain indirect information based on the

68 arrival of new immigrants (Cote \& Clobert 2007b; Cote, Boudsocq \& Clobert 2008; Cote \&

69 Clobert 2012) and the failure of emigrants to find a new populations (Cote \& Clobert 2007a).

70 Likewise, some spider species, use both direct sampling of information on density, habitat

71 quality, and wind direction (Bonte et al. 2003a; Bonte et al. 2003b; Bonte, Bossuyt \& Lens 2007;

72 Bonte, Van Belle \& Maelfait 2007; De Meester \& Bonte 2010) as well as indirect information

73 such as the number of other individuals dispersing (De Meester \& Bonte 2010). Yet it remains

74 unclear how prevalent use of indirect information in dispersal might be across species.

75 Widespread use of indirect information would dramatically alter our understanding of dispersal

76 and would have consequences for both fundamental work in ecology and evolution as well as

77 applied conservation.

78 Using a theoretical model, we show that simple rules for the use of indirect social

79 information in dispersal decisions can evolve under a broad range of conditions and therefore

80 might be quite common in nature. We investigated the evolution of information use prior to 
81 dispersal using a simple metapopulation model in which we allowed information use in dispersal

82 to evolve. We were primarily interested in whether the use of indirect information provided by

83 immigrants could evolve, and if so, could it evolve in competition with direct information about

84 local density.

85

86

THE MODEL

87

We constructed an individual-based model of informed dispersal behavior, based on

information about the local density and/or the number of immigrants, while simplifying the

landscape and genetic features of the system. This individual-based model follows a

91 female-based life cycle with two age-classes (individuals in the population are juveniles from

92 birth until age 1 , subadults from age 1 to 2 , and adults after age 2 ) and age-specific survival and

93 fecundity (Caswell 2001, and see Fig. 1). Only juveniles dispersed and this dispersal depended

94 on baseline uninformed dispersal that alleviates kin competition (U) and informed dispersal (D

95 and I) as described below. Our basic model used a 'fast' life history roughly equivalent to a small

96 lizard or passerine life cycle (survival: $\mathrm{s}_{0}=0.2, \mathrm{~s}_{1}=0.35, \mathrm{~s}_{2}=0.5$; fecundity: $\mathrm{f}_{1}=7, \mathrm{f}_{2}=7$, see

97 Schoener et al. 2003; Legendre et al. 2008). In each patch, discrete time structured population

98 dynamics were modeled. Juveniles were given the opportunity to disperse to other patches prior

99 to the subsequent reproductive episode if they survived their first year. All patches were equally

100 connected (leading to lower kin competition) and population size was limited at reproduction by

101 the maximum patch carrying capacity which was the same for all patches $(K=100)$. This

102 configuration leads to very stable populations with low levels of demographic stochasticity,

103 lower kin competition, and very small benefits of dispersal (populations are all similarly near $K$ ) 
104 essentially creating a conservative scenario for the evolution of informed dispersal. Subsequent

105 simulations introduced increased stochasticity to explore the benefits of information use under

106 other scenarios (see SOM).

107 Basic Loop

108 The simulation is in discrete time. Individuals are described by their age, the values of

109 their adaptive traits, their patch of residence, their dispersal status, the strategy they played if

110 they dispersed, the probability of dispersal, and the cost of dispersal.

111 At each time step, the following operations are performed:

112

Survival

Reproduction and mutation

Dispersal

Increase time step

116 1) Survival: Surviving juveniles become subadults, surviving subadults become adults, and

117 adults have a constant survival rate. Survival was determined by a Bernoulli draw according to

118 the age-specific survival.

119 2) Reproduction: Subadults and adults reproduced according to their age-specific reproductive

120 rate. Fecundity was drawn using a Poisson distribution, but limited by the patch carrying

121 capacity.

122 3) Mutation: Offspring inherited their parental dispersal genotype (coefficients of the dispersal

123 functions, $D$ and $I$, described below) with a 0.02 probability of mutation. The degree of mutation

124 on $D, I$, and $U$ in later models (see additional results in SOM) was set by a random draw from a

125 Gaussian distribution with a standard deviation of 0.02. These mutations have the effect of 
126 causing a slight alteration in how intensely the dispersal decision will respond to a given set of

127 local cues (local density and number of immigrants).

128 4) Dispersal: Offspring were given the opportunity to disperse according to their dispersal

129 strategy (i.e. genotype), and current conditions that informed their dispersal strategy. Specific

130 dispersal strategy functions are described below. Since the first individuals to disperse at a given

131 time step would only have access to local density information (no immigrants possible since

132 nobody has yet dispersed), we randomized at each time step the order in which individuals were

133 selected for dispersal across the whole metapopulation. We chose to model dispersal behavior on

134 current density and immigrant number rather that everyone using the same values from the

135 previous time step because it reflects a much more biologically realistic mechanism for

136 information use in dispersal as newborns gather information about their surroundings(Matthysen

137 2012). If an individual juvenile dispersed, it could die during dispersal according to the costs of

138 dispersal (varied in simulations from 0-0.1 in additional results; see SOM) or arrive at a new

139 destination patch. This cost of dispersal modified the juvenile survival rate $\left(\mathrm{s}_{0} \times(1\right.$-cost $\left.)\right)$.

140 Juveniles who survived dispersal, were randomly assigned a new patch, excluding their natal

141 patch, and were then counted as an immigrant for that new patch.

142 Initiation of the simmulation began with the creation of 100 subadult individuals with

143 identical genotype in a single patch. Individuals then reproduced and their offspring who

144 dispersed began to colonize the patches.

Dispersal Functions

147 We modeled two forms of information use that could influence dispersal: 1) a measure of

148 the local density which are known to provide a benefit to dispersal behavior (Cadet et al. 2003) 
149 and 2) a measure of the number of immigrants entering a patch (Cote \& Clobert 2007a). Local

150 density directly influences reproductive success whereas the number of arriving immigrants

151 indicates that other populations are attainable and may provide some information about overall

152 metapopulation density. The influence of local density and immigrant-borne information on

153 dispersal behavior $\left(B_{x}\right)$ were modeled as:

154

155

Density-dependent: $\quad B_{D}=D \frac{n_{i}}{K_{i}}-2$

156

157

Immigrant-dependent : $\quad B_{I}=\mathfrak{I}_{i}-2$

158

159 where $n_{i}$ is the number of individuals in patch $i, K_{i}$ is the patch carrying capacity $K$, and $M_{i}$ is the

160

number of immigrants entering the patch. The coefficients ( $D$ and $I$ ) influenced the intensity of

161 these behaviors and each was free to evolve independently of the others. Immigrant-dependent

162 dispersal only occurred if immigrants were present (i.e. if $M_{i}>0$ ). Fixed intercepts (-2) were

163 included to set a lower limit to dispersal via each form of information use at $12 \%$. This intercept

164 allowed dispersal to evolve more rapidly without having an impact on the evolved dispersal rate

165 which was always significantly higher (see SOM, Fig. S8). We assumed haploid genetics and

166 clonal reproduction with mutation in 'genes' for the coefficients ( $D$ and $I$ ) that affect each

167 informed-dispersal strategy as described above. These behaviors were then used to determine the

168 probability of dispersal, $d(x)$, associated with density $\left(d_{\mathrm{D}}\right)$ and immigrant $\left(d_{\mathrm{I}}\right)$ information sources

169 using the following function:

170 


$$
d(x)=\frac{1}{1+\exp (-x)}
$$

173 where $x$ is the influence of each form of information described by equations 1 and $2\left(x=B_{D}\right.$ or $\left.174 B_{I}\right)$. This function allowed us to convert the biologically meaningful relationships described in 175 equations 1 and 2 to probabilities of dispersal $d_{\mathrm{D}}$ and $d_{\mathrm{I}}$ respectively.

176 Because immigrant-dependent dispersal can only occur if immigrants exist (i.e. some 177 dispersal already occurs), we also included a fixed parameter for baseline uninformed dispersal $178\left(d_{\mathrm{U}}=0.1\right)$. Uninformed dispersal should alleviate kin competition and increased values when 179 allowed to evolve would be favored when kin competition is higher. Dispersal was always drawn 180 for uninformed dispersal first $\left(d_{U}\right)$ and then for informed dispersal $\left(d_{D}\right.$ or $\left.d_{I}\right)$. Removal of this 181 baseline dispersal prevents the evolution of immigrant-dependent dispersal when alone (I-only 182 models) since there were no immigrants, but it had little influence on the evolution of 183 density-dependent dispersal (D-only models) or both density and immigrant-dependent dispersal 184 when both were present (D\&I models; Fig. S9). Allowing this baseline uninformed dispersal (U) 185 to evolve had little effect on the evolution of informed dispersal (D-only, I-only, or D\&I; Fig. 186 S10).

We constructed alternative models of information use to examine the independent effects of density (D-only) or immigrants (I-only) on dispersal as well as their joint co-evolutionary dynamics when individuals could use both forms of information simultaneously (D\&I). In models including both density- and immigrant-dependent information (D\&I), all individuals

191 were capable of using both sources of information and the sum of the two sources of information 192 determined the dispersal probability. This assumption matches empirical findings that individuals 193 use multiple sources of information in decision making (Le Galliard et al. 2003; Cote \& Clobert 
194 2007b; Cote et al. 2008; Clobert et al. 2009; Clobert et al. 2012b; Cote \& Clobert 2012;

195 Matthysen 2012). In the case of simultaneous models the individual dispersed with probability $d_{\mathrm{D}}$

$196+d_{\mathrm{I}}$ if $d_{\mathrm{D}}+d_{\mathrm{I}}<1$, and always dispersed if $d_{\mathrm{D}}+d_{\mathrm{I}}>1$. We calculated the 'realized' informed

197 dispersal rates attributed to each information source by a random draw using the relative

198 dispersal probability of each information source $\left(d_{\mathrm{D}}\right.$ or $\left.d_{\mathrm{I}}\right)$. The probabilities $d_{\mathrm{D}}$ and $d_{\mathrm{I}}$ represent

199 the incentive of an individual to disperse according to density or immigrant information, and are

200 not the realized dispersal rates associated with each strategy. These realized dispersal rates were

201 computed as the total number of individuals dispersing according to each strategy divided by the

202 total number of individuals in the metapopulation.

203 We determined the probability that informed dispersal evolved and the dispersal rate

204 associated with information use using Monte Carlo simulations of 100 trajectories over $1.5 \times 10^{6}$

205 time steps for each set of parameters and each model case. Because all individuals were capable

206 of information use from one or two sources, then all values of the evolved coefficient potentially

207 existed in the population unless the entire metapopulation went extinct. Therefore, we

208 determined that 'evolution' of an informed dispersal strategy had occurred if the evolved

209 coefficient was greater than 0 more often than by chance across simulations since drift should

210 lead to negative coefficients as often as positive ones. This approach gives similar results to

211 quantify evolution if it increases above an estimate of random drift as presented in the

212 supplemental materials (see SOM).

213 Our initial model exploration focused on the use of density and immigrant sources of

214 information and the coevolution of both forms when together. Subsequent models (see SOM)

215 explored the effects of variation in life history, carrying capacity, patch number, environmental

216 stochasticity, the costs of dispersal (Bonte et al. 2012), variation in baseline dispersal ( $\left.d_{\mathrm{U}}\right)$, the 
217 order in which different sources of information are used, and the immigrant information use 218 strategy function.

219

220

\section{RESULTS}

221

222 Evolution of Information Use: single source of information

223

We found that informed dispersal could evolve and drive dispersal behavior and

224 metapopulation dynamics under a broad range of contexts. Consistent with other models (Travis et al. 1999; Ronce 2007), we found that density dependent dispersal evolves when it is the only source of information (Fig. 2a, 3). Here we show that the arrival of immigrants also provides useful information that can drive dispersal behavior (Fig. 2b, 3). Indeed, information-dependent dispersal coefficients (D and I) were significantly biased towards positive values in contrast to expectations from drift which should lead to an equal probability of positive and negative values

(Sign test: D-only: 97/100 positive trials, $\mathrm{P}<0.0001$; I-only: 99/100 positive trials, $\mathrm{P}<0.0001$ ).

Both density and immigrant dependent dispersal evolved even when each was in competition with uninformed dispersal (fixed $d_{\mathrm{U}}=10 \%$ and when $\mathrm{U}$ was allowed to evolve; see SOM and Fig. S9, S10a) and lead to increased dispersal from that source of information (Fig. 2a,b) despite a highly stable and homogenous landscape. Dispersal reaction norms due to information use illustrate this nicely: local density and immigrant number influence dispersal (Fig. 4a and b respectively) at equilibrium compared to a flat, fixed dispersal rate of uninformed dispersal. Density-dependent dispersal shows a steady increase in dispersal as local density rises (Fig. 4a). In contrast, immigrant-dependent dispersal shows a rapid increase in dispersal with the first few

239 immigrants and then quickly asymptotes at high levels of dispersal (Fig. 4b). 
For informed dispersal to evolve there must be some benefit to these strategies.

241

242

243

\section{3}

Individuals benefit from dispersal when they find a new population with a lower density given that fitness is density-dependent. We compared the density of the new destination patch and an individual's original patch right before reproduction to estimate the benefit of dispersal to that individual. Informed dispersal led to discovery of a less dense patch than the population of origin on average. Both density and immigrant information seemed to present very similar advantages early in the evolutionary process (Fig. S5a,b and Fig. 5a). However, the benefit of informed dispersal was extremely slight (0.5-0.02\%) since the landscape was largely homogenous and most populations were very close to their carrying capacity at all times. Environmental stochasticity augmented spatial heterogeneity in patch density and led to a larger benefit during the evolution of informed dispersal (Fig. 5a; Fig. S5; see also McPeek \& Holt 1992; Travis \& Dytham 1999).

\section{Evolution of Information Use: multiple sources of information}

Coexistence of density and immigrant dependent dispersal occurred often in our model when both forms of information use were possible (48\% of simulations for model D\&I; Fig. 2c and 3). Information-dependent dispersal coefficients for both behaviors (D and I) were again significantly biased towards positive values overall in contrast to expectations from drift (Sign test for D\&I model: D: 65/100 positive trials, $\mathrm{P}=0.035$; I: 82/100 positive trials, $\mathrm{P}<0.0001$ ). Reaction norms of density- and immigrant-dependent dispersal both show increases with density or immigrant number respectively and rise well above background levels of uninformed dispersal (Fig. 4c,d). If we contrast these reaction norms to the reaction norms that evolve when only one form of information use is possible, we see that the slope of density dependent dispersal 
263 decreases considerably (Fig. 4a vs. c) whereas the shape of the immigrant-dependent dispersal

264 curve changes only slightly (Fig. 4b vs. d; dispersal above $98 \%$ at 3 vs. 5 immigrants

265 respectively). Optimal levels of density-dependent dispersal therefore shift considerably when

266 another source of information affects dispersal. In contrast, immigrant-dependent information

267 has large effects on dispersal with the arrival of the first few immigrants and this trigger does not

268 change much when other sources of information are available.

269 While both forms of dispersal evolved less often when both were present (a decrease of

$27032 \%$ and $17 \%$ for density and immigrant dependent dispersal respectively), coexistence remained

271 high when in competition with a second source of information (D\&I) relative to models where

272 just one strategy was possible (D-only or I-only; Fig. 3). Joint evolution of both information use

273 behaviors occurred even in competition with uninformed baseline dispersal (see SOM, Fig. S9,

274 S10, S11).

275 Informed dispersal showed benefits at the metapopulation level when both forms of

276 information were used together relative to using just one source of information. This benefit was

277 most apparent when demographic stochasticity increased. Lower population carrying capacities

278 raised the risk of extinction due to increased demographic stochasticity, and for a narrow window

279 of carrying capacities the use of two sources of information helped reduce the risk of extinction

280 for the metapopulation as a whole by $20-40 \%$ relative to use of just one source of information

281 (Fig. 5d). At slightly lower carrying capacities, when metapopulation extinction always occurred,

282 the use of two different sources of information lead to longer persistence (200-10000 time steps

283 or roughly 100-5000 generations; Fig. S3) of the metapopulation than if just one source of

284 information was used. An increase in the frequency of environmental stochasticity lead to higher

285 metapopulation extinction, and the risk of extinction was lower when one or more sources of 
286 information was available (D-only or I-only or D\&I) compared to uninformed dispersal only 287 (U-only) (Fig. 5c).

288

289 DISCUSSION AND SYNTHESIS

290

291

Our results show that informed dispersal evolves under a broad array of contexts and that

292 both density and indirect immigrant-dependent information sources evolve and can coexist. The

293 frequent evolution of informed dispersal in the very conservative setup examined here (e.g.

294 stable metapopulation) suggests that use of a variety of information sources, including indirect

295 measures of the metapopulation landscape, could be common in nature. Indeed, direct

296 information use in dispersal decisions is widespread (Ims \& Hjermann 2001; Matthysen 2005;

297 Ronce 2007; Clobert et al. 2009; Schmidt et al. 2010) and the few empirical investigations of

298 indirect information use that we are aware of have found evidence for it despite a broad

299 taxonomic range. For example, common lizards modify their dispersal behavior in response to

300 immigrants who appear to provide information about the density of their natal population (Cote

301 \& Clobert 2007a). Likewise, our recent work in Tetrahymena ciliates shows that residents alter

302 their dispersal rate when arriving immigrants come from populations that differ in density or

303 social structure. In both of these empirical examples, immigrants carry more information (e.g.

304 population density) than we included in our model. This additional information should serve to

305 increase the fitness benefits of immigrant-dependent dispersal suggesting that we have probably

306 underestimated the likelihood that it evolves.

307 For use of both information sources to evolve, there must be benefits to adjust behavior

308 using two sources of information rather than a single source. Benefits of density-dependent 
309 dispersal are well known since movement out of high density patches should have direct fitness

310 benefits when reproduction is density dependent (Travis et al. 1999; Matthysen 2005; Cote et al.

311 2008). Our results demonstrate that even under very conservative conditions, immigrant

312 dependent dispersal also presents a benefit and evolves. Likewise, coexistence of density- and

313 immigrant-dependent dispersal even under the stable meta-population structure that we modeled

314 suggests that these behaviors can evolve and coexist frequently even when the benefits of each

315 behavior are low. Coexistence also implies that neither source of information carries benefits that

316 would cause competitive exclusion of the other information source. Using two sources of

317 information also provided additional benefits and could play an important role in metapopulation

318 stability, especially as increased stochasticity creates larger inequalities in population densities.

319 The benefits of using multiple information sources (decreased extinction risk) that we measured

320 occurred for a small range of meta-population conditions (medium levels of stochasticity), but

321 they suggest an important advantage to informed dispersal under less stable conditions of most

322 real meta-populations. While the benefits we measured in our model were small in the relatively

323 homogenous landscape we constructed, conditions that more realistically imitate empirical

324 landscapes should confer much larger benefits to this behavior.

325 Joint evolution of density and immigrant dependent dispersal would be prevented if

326 information content of density and immigrant number were not sufficiently different or if one

327 information source was superior to the other (Enfjäll \& Leimar 2009; Hovestadt et al. 2010;

328 Schmidt et al. 2010; Bocedi et al. 2012). Immigrant arrival might be related to the overall density

329 of the metapopulation since populations that have more individuals will generate more

330 dispersers, and therefore immigrants, even through a fixed baseline dispersal rate. This estimate

331 of the overall metapopulation density contrasts to density-dependent measures of the local 
332 population alone. Competitive exclusion might be expected since immigrant number should be

333 more decoupled with local fitness in any single patch and thus dispersal should carry a higher

334 variance in benefits relative to direct information on local density. In simulations where we

335 introduced a difference in the cost of using each form of information (Figs. S6, S7), the most

336 costly form of information did not evolve-although this cost is not directly linked to the quality

337 of information. More frequently, we found coexistence of information use through both density

338 and immigrant information. This suggests that each source of information is not fully redundant

339 and that one source of information is not necessarily superior to the other. This equivalency of

340 information can serve as an advantage under some contexts (e.g. when stochasticity is high; Fig.

3415 and S3) and would be especially useful where the costs of information use from one source

342 might constrain dispersal below an optimal level (Bocedi et al. 2012). Likewise, if immigrants

343 also carry additional information about their populations (Cote \& Clobert 2007a) or help orient

344 dispersers towards certain populations, then we could expect the benefits of indirect information

345 use to be even more advantageous.

346 The potential prevalence of informed dispersal has a number of important implications

347 for both fundamental and applied ecology. In basic ecological research, the use of information

348 has recently been explored in terms of density dependent dispersal, and this simple behavior

349 greatly effects how movement influences population persistence (Ims \& Hjermann 2001; Cadet

350 et al. 2003; Matthysen 2005). Earlier models of 'informed' dispersal—such as 'ideal free

351 distribution' models — generally assumed perfect knowledge of the landscape (Abrahams 1986;

352 Gray \& Kennedy 1994; Holt \& Barfield 2001) which presumably was acquired through

353 prospecting that carried low costs. Low cost prospecting might work when patches are close (e.g.

354 foraging patches), but is less realistic when habitat patches are more distant. The use of indirect 
355 information, such as the arrival of immigrants, could provide another mechanism by which the

356 ideal free distribution is achieved (Baguette, Clobert \& Schtickzelle 2010). If immigrant arrival

357 is linked to overall metapopulation density and if immigrants carry additional information about

358 the quality of those habitats as suggested in empirical examples (Cote \& Clobert 2007a), then we

359 might approach an ideal free distribution through use of indirect information transfer across the

360 landscape. Deviation from ideal free models might then in part reflect the quality or reliability of

361 that indirect information transfer (see also Abrahams 1986; Gray \& Kennedy 1994; Chaine \&

362 Clobert 2012). Most likely, individuals use a number of sources of information on local

363 conditions, direct prospecting of nearby patches, and indirect measures of the landscape such as

364 immigrant-borne information (Clobert et al. 2009). If this form of information use is prevalent,

365 then we must shift our view of dispersal from largely random movement among populations to

366 much more targeted and informed movement patterns that approach ideal-free expectations.

368 dispersal and metapopulation dynamics usually ignore the important role that information

369 transfer across the landscape might play in guiding subsequent dispersal decisions. Applied

370 management or conservation efforts to increase connectivity or gene flow might be greatly

371 hampered if we do not also introduce the indirect cues that influence dispersal. Indeed, the highly

372 variable success of artificial corridors (Gilbert-Norton et al. 2010) could in part be caused by the

373 lack of indirect information since immigrants will be rare when a new corridor is first

374 constructed (see also Le Galliard et al. 2003). More generally, conservation efforts could be

375 greatly aided by modifying natural dispersal through the manipulation of information that is

376 accessible to residents rather than by costly alterations of the landscape between habitat patches

377 (Chaine \& Clobert 2012). As we show here, access to multiple sources of information may better 
378 mitigate extinction risk in highly stochastic environments compared to situations where little

379 information exists. Broader inclusion of how information is used in dispersal should provide us

380 with new tools for conservation and fundamentally modify our approach to conservation ecology

381 and the management of populations in peril.

382 Our findings also have important implications for dispersal theory and the incorporation

383 of information use into this field. We found the evolution of both forms of informed dispersal

384 despite potentially large differences in the quality of information gleaned from each source.

385 Whereas local density directly affects fitness, immigrant arrival at best gives some indication of

386 surrounding population sizes when density dependent dispersal exists and at worst simply

387 provides evidence that other populations exist. Coexistence of the two sources of information

388 suggests that the quality of information may be somewhat less important than the presence of

389 that information. In support of this notion, models of indirect information use based on

390 immigrant presence rather than immigrant number show very similar results (Fig. S12). This

391 result is empirically supported by the fact that dispersal in the common lizard was found to be

392 sensitive to the presence and not to the quantity of immigrants (Cote \& Clobert 2007a).

393 Similarly, recent models of density dependent information use suggest that the precision of

394 information provides diminishing returns and high quality information is not optimal when it

395 also incurs elevated costs associated with gathering additional precision (Bocedi et al. 2012).

396 Both of these investigations adopt very simple dispersal contexts and yet both show that

397 information use in dispersal evolves quite readily and should be common in nature. More

398 generally, the passive information transfer across the landscape that evolves in our models could

399 be an important first evolutionary step that allows more active information transfer and

400 communication to evolve both within populations and across landscapes. 


\section{ACKNOWLEDGEMENTS}

403

404 We thank O. Ronce and B. Lyon for comments on an early draft and discussions on this topic and 405 anonymous reviewers for additional comments. J.C. was supported by French ANR BLANC 406 grants DIAME and INDHET, and program Biodiversa TenLamas. J.C. and A.S.C. received 407 support from the CNRS and ANR-INFO-EVO-ECO, and A.S.C received support from 408 ANR-JCJC NetSelect. This work is part of the Laboratoire d'Excellence (LABEX) entitled 409 TULIP (ANR-10-LABX-41).

410

\section{REFERENCES}

413 Abrahams, M. V. 1986. Patch choice under perceptual constraints: a cause for departures from an 414 ideal free distribution. Behavioral Ecology and Sociobiology, 19, 409-415.

415 Avarguès-Weber, A., Dawson, E. H. \& Chittka, L. 2013. Mechanisms of social learning across 416 species boundaries. Journal of Zoology, earlyview.

417 Baguette, M., Clobert, J. \& Schtickzelle, N. 2010. Metapopulation dynamics of the bog fritillary 418 butterfly: experimental changes in habitat quality induced negative density-dependent dispersal. 419 Ecography, 170-176.

420 Blanchet, S., Clobert, J. \& Danchin, É. 2010. The role of public information in ecology and 421 conservation : an emphasis on inadvertent social information. Annals of the New York Academy 422 of Sciences, 1195, 149-168. 
423 Bocedi, G., Heinonen, J. \& Travis, J. M. J. 2012. Uncertainty and the role of information

424 acquisition in the evolution of context-dependent emigration. American Naturalist, 179, 606-620.

425 Bonnie, K. E. \& Earley, R. L. 2007. Expanding the scope for social information use. Animal

426 Behaviour, 74, 171-181.

427 Bonte, D., Bossuyt, B. \& Lens, L. 2007. Aerial dispersal plasticity under different wind 428 velocities in a salt marsh wolf spider. Behavioral Ecology, 18, 438-443.

429 Bonte, D., Lens, L., Maelfait, J.-P., Hoffmann, M. \& Kuijken, E. 2003a. Patch quality and 430 connectivity influence spatial dynamics in a dune wolfspider. Oecologia, 135, 227-233.

431 Bonte, D., Van Belle, S. \& Maelfait, J.-P. 2007. Maternal care and reproductive state-dependent 432 mobility determine natal dispersal in a wolf spider. Animal Behaviour, 74, 63-69.

433 Bonte, D., Van Dyck, H., Bullock, J. M., Coulon, A., Delgado, M., Gibbs, M., Lehouck, V., 434 Matthysen, E., Mustin, K., Saastamoinen, M., Schtickzelle, N., Stevens, V. M., Vandewoestijne, 435 S., Baguette, M., Barton, K., Benton, T. G., Chaput-Bardy, A., Clobert, J., Dytham, C., 436 Hovestadt, T., Meier, C. M., Palmer, S. C. F., Turlure, C. \& Travis, J. M. J. 2012. Costs of 437 dispersal. Biological Reviews, 87, 290-312.

438 Bonte, D., Vandenbroecke, N., Lens, L. \& Maelfait, J.-P. 2003b. Low propensity for aerial 439 dispersal in specialist spiders from fragmented landscapes. Proceedings of the Royal Society of 440 London. Series B: Biological Sciences, 270, 1601-1607.

441 Bowler, D. E. \& Benton, T. G. 2005. Causes and consequences of animal dispersal strategies:

442 relating individual behaviour to spatial dynamics. Biological Reviews, 80, 205-225.

443 Cadet, C., Régis Ferrière, Johan A. J. Metz \& van Baalen, M. 2003. The Evolution of Dispersal 444 under Demographic Stochasticity. American Naturalist, 162, 427-441. 
445 Caswell, H. 2001. Matrix population models: Construction, analysis and interpretation.

446 Sunderland, MA: Sinauer Associates.

447 Chaine, A. S. \& Clobert, J. 2012. Dispersal. In: Behavioral responses to a changing world (Ed.

448 by U. Candolin \& B. B. M. Wong), pp. 63-79. Oxford: Oxford University Press.

449 Chaine, A. S., Schtickzelle, N., Polard, T., Huet, M. \& Clobert, J. 2010. Kin-based recognition

450 and social aggregation in a ciliate. Evolution, 64, 1290-1300.

451 Clobert, C., Baguette, M., Benton, T. G. \& Bullock, J. M. 2012a. Disersal ecology and evolution.

452 Oxford: Oxford University Press.

453 Clobert, J., Danchin, E., Dhondt, A. A. \& Nichols, J. D. 2001. Dispersal. New York: Oxford 454 Univ Press.

455 Clobert, J., Galliard, J.-F. L., Cote, J., Meylan, S. \& Massot, M. 2009. Informed dispersal, 456 heterogeneity in animal dispersal syndromes and the dynamics of spatially structured 457 populations. Ecology Letters, 12, 197-209.

458 Clobert, J., Massot, M. \& Le Galliard, J.-F. 2012b. Multi-determinism in natal dispersal: the 459 common lizard as a model system. In: Dispersal Ecology and Evolution (Ed. by J. Clobert, M.

460 Baguette, T. G. Benton \& J. M. Bullock), pp. 29-37. Oxford, UK: Oxford University Press.

461 Cote, J., Boudsocq, S. \& Clobert, J. 2008. Density, social information, and space use in the 462 common lizard (Lacerta vivipara). Behavioral Ecology, 19, 163-168.

463 Cote, J. \& Clobert, J. 2007a. Social information and emigration: lessons from immigrants.

464 Ecology Letters, 10, 411-417.

465 Cote, J. \& Clobert, J. 2007b. Social personalities influence natal dispersal in a lizard.

466 Proceedings of the Royal Society B: Biological Sciences, 274, 383-390. 
467 Cote, J. \& Clobert, J. 2012. Dispersal syndromes in the common lizard: personality traits, 468 information use and context-dependent dispersal decisions. In: Dispersal Ecology and Evolution 469 (Ed. by J. Clobert, M. Baguette, T. G. Benton \& J. M. Bullock), pp. 152-158. Oxford, UK: 470 Oxford University Press.

471 Dall, S. R. X., Giraldeau, L.-A., Olsson, O., McNamara, J. M. \& Stephens, D. W. 2005.

472 Information and its use by animals in evolutionary ecology. Trends in Ecology and Evolution, 20, $473 \quad 187-193$.

474 Danchin, E., Giraldeau, L.-A., Valone, T. J. \& Wagner, R. H. 2004. Public Information: From 475 Nosy Neighbors to Cultural Evolution. Science, 305, 487-491.

476 De Fraipont, M., Clobert, J., John, H. \& Alder, S. 2000. Increased pre-natal maternal 477 corticosterone promotes philopatry of offspring in common lizards Lacerta vivipara. Journal of 478 Animal Ecology, 69, 404-413.

479 De Meester, N. \& Bonte, D. 2010. Information use and density-dependent emigration in an 480 agrobiont spider. Behavioral Ecology, 21, 992-998.

481 Doligez, B., Danchin, E. \& Clobert, J. 2002. Public information and breeding habitat selection in 482 a wild bird population. Science, 297, 1168-1170.

483 Enfjäll, K. \& Leimar, O. 2009. The evolution of dispersal - the importance of information about 484 population density and habitat characteristics. Oikos, 118, 291-299.

485 Gilbert-Norton, L., Wilson, R., Stevens, J. R. \& Beard, K. H. 2010. A Meta-Analytic Review of 486 Corridor Effectiveness. Conservation Biology, 24, 660-668.

487 Gray, R. D. \& Kennedy, M. 1994. Perceptual constraints on optimal foraging: a reason for 488 departures from the ideal free distribution? Animal Behaviour, 47, 469-471. 
489 Greene, E. 1987. Individuals in an osprey colony discriminate between high and low quality

490 information. Nature, 329, 239-241.

491 Hanski, I. A. \& Gaggiotti, O. E. 2004. Ecology, Genetics and Evolution of Metapopulations.

492 Amsterdam: Academic Press.

493 Holt, R. D. \& Barfield, M. 2001. On the relationship between the ideal free distribution and the 494 evolution of dispersal. In: Dispersal (Ed. by J. Clobert, E. Danchin, A. A. Dhondt \& J. D. 495 Nichols), pp. 83-95. Oxford, UK: Oxford University Press.

496 Hovestadt, T., Kubisch, A. \& Poethke, H.-J. 2010. Information processing in models for 497 density-dependent emigration: A comparison. Ecological Modelling, 221, 405-410.

498 Ims, R. A. \& Hjermann, D. 2001. Condition dependent dispersal. In: Dispersal (Ed. by J.

499 Clobert, E. Danchin, A. Dhondt \& J. D. Nichols), pp. 203-216. New York: Oxford University 500 Press.

501 Le Galliard, J. F., Ferriere, R. \& Clobert, J. 2003. Mother-offspring interactions affect natal 502 dispersal in a lizard. Proceedings of the Royal Society B, 270, 1163-1169.

503 Legendre, S., Schoener, T. W., Clobert, J. \& Spiller, D. A. 2008. How is extinction risk related to 504 population-size variability over time? A family of models for species with repeated extinction 505 and immigration. American Naturalist, 172, 282-298.

506 Léna, J.-P., Clobert, J., de Fraipont, M., Lecomte, J. \& Guyot, G. 1998. The relative influence of 507 density and kinship on dispersal in the common lizard. Behavioral Ecology, 9, 500-507.

508 Matthysen, E. 2005. Density-dependent dispersal in birds and mammals. Ecography, 28, 509 403-416. 
510 Matthysen, E. 2012. Multicausality of dispersal In: Dispersal Ecology and Evolution (Ed. by J.

511 Clobert, M. Baguette, T. G. Benton \& J. M. Bullock), pp. 3-12. Oxford, UK: Oxford University

512 Press.

513 McPeek, M. A. \& Holt, R. D. 1992. The evolution of dispersal in spatially and temporally

514 varying environments. American Naturalist, 140, 1010-1027.

515 Nathan, R., Getz, W. M., Revilla, E., Holyoak, M., Kadmon, R., Saltz, D. \& Smouse, P. E. 2008.

516 A movement ecology paradigm for unifying organismal movement research. Proceedings of the

517 National Academy of Sciences, USA, 105, 19052-19059.

518 Ronce, O. 2007. How Does It Feel to Be Like a Rolling Stone? Ten Questions About Dispersal

519 Evolution. Annual Review of Ecology, Evolution, and Systematics, 38, 231-253.

520 Ronce, O., Olivieri, I., Clobert, J. \& Danchin, E. 2001. Perspectives on the study of dispersal

521 evolution. In: Dispersal (Ed. by J. Clobert, E. Danchin, A. Dhondt \& J. D. Nichols), pp.

522 341-357. New York: Oxford University Press.

523 Schmidt, K. A., Dall, S. R. X. \& Van Gils, J. A. 2010. The ecology of information: an overview

524 on the ecological significance of making informed decisions. Oikos, 119, 304-316.

525 Schoener, T. W., Clobert, J., Legendre, S. \& Spiller, D. A. 2003. Life-history models of

526 extinction: A test with island spiders. American Naturalist, 162, 558-573.

527 Travis, J. M. J. \& Dytham, C. 1999. Habitat persistence, habitat availability and the evolution of 528 dispersal. Proceedings of the Royal Society of London. Series B: Biological Sciences, 266, $529 \quad 723-728$.

530 Travis, J. M. J., Murrell, D. J. \& Dytham, C. 1999. The evolution of density-dependent dispersal.

531 Proceedings of the Royal Society of London. Series B: Biological Sciences, 266, 1837-1842. 


\section{Figure 1}

Life cycle of organisms in the model

Diagram of the basic life cycle of individuals in the model. The two age classes of reproductive individuals (subadults aged 1 year, and adults aged 2 years and more) are described by their age-specific survival (s) and fecundity $(f)$. Individuals disperse during the juvenile stage from age 0 to 1 , indicated by *.

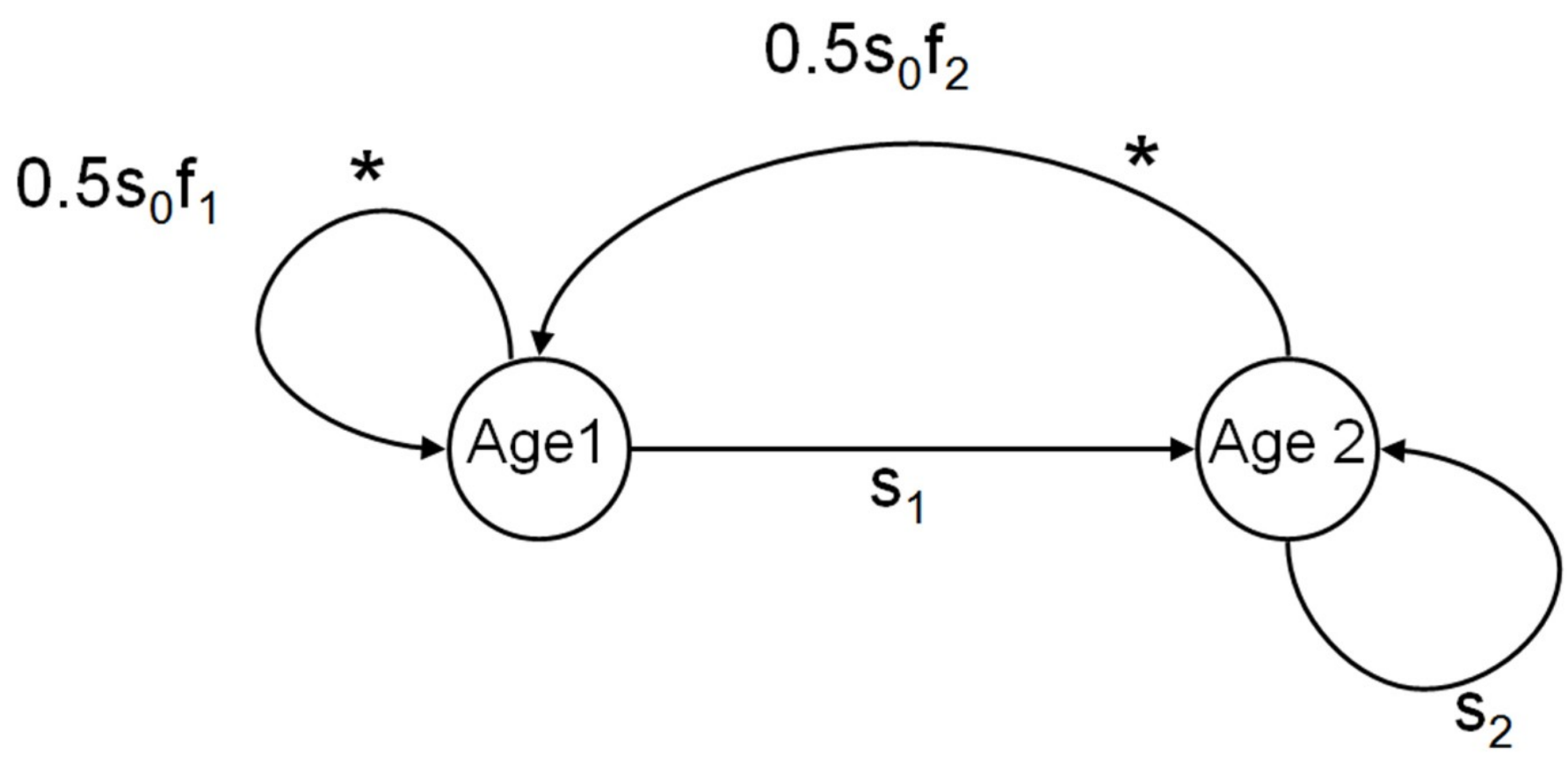




\section{Figure 2}

Temporal dynamics of the evolution of informed dispersal

Temporal dynamics of the evolution of information based dispersal due to local density ( $d_{\mathrm{D}}$ in red) and the number of arriving immigrants ( $d_{\mathrm{I}}$ in blue). Trajectories reflect average dispersal rates for 100 Monte Carlo simulations. A) Dynamics of immigrant number information use alone $\left(\mathrm{d}_{\mathrm{I}}\right)$. B) Dynamics of density dependent information use alone $\left(\mathrm{d}_{\mathrm{D}}\right)$. C) Dynamics of both density dependent and immigrant dependent information when used simultaneously (D\&I) with no cost of dispersal. Uninformed dispersal is fixed at $10 \%$ and does not evolve. The $95 \%$ confidence interval is shown for the last time step on each trajectory.
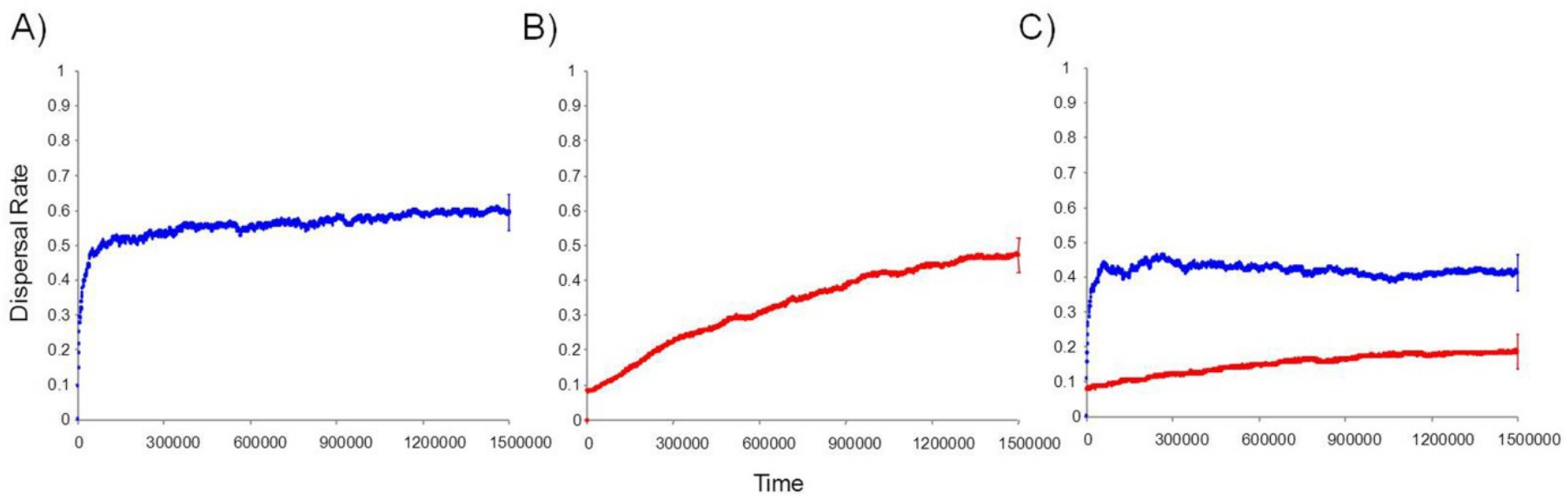


\section{Figure 3}

\section{Evolution of information use}

Probability that each form of information use evolves. Plotted are the proportion of simulations where dispersal evolved based on density dependent information (D, red), immigrant information (I, blue), both density and immigrant information (D+I, red and blue hatch), or where dispersal did not evolve (None, white) across 100 Monte Carlo simulations. D-alone and I-alone are for models with just one source of information available (plus U fixed at 10\%). D\&I is a model with both density and immigrant dependent dispersal present. Probability that each form of information use evolves. Plotted are the proportion of simulations where dispersal evolved based on density dependent information (D, red), immigrant information (I, blue), both density and immigrant information (D+I, red and blue hatch), or where dispersal did not evolve (None, white) across 100 Monte Carlo simulations. D-alone and I-alone are for models with just one source of information available (plus $U$ fixed at 10\%). D\&I is a model with both density and immigrant dependent dispersal present. Probability that each form of information use evolves. Plotted are the proportion of simulations where dispersal evolved based on density dependent information (D, red), immigrant information (I, blue), both density and immigrant information (D+I, red and blue hatch), or where dispersal did not evolve (None, white) across 100 Monte Carlo simulations. D-alone and I-alone are for models with just one source of information available (plus U fixed at 10\%). D\&I is a model with both density and immigrant dependent dispersal present. 


$$
\Delta 1 \quad D+1 \quad \Delta D \text { None }
$$

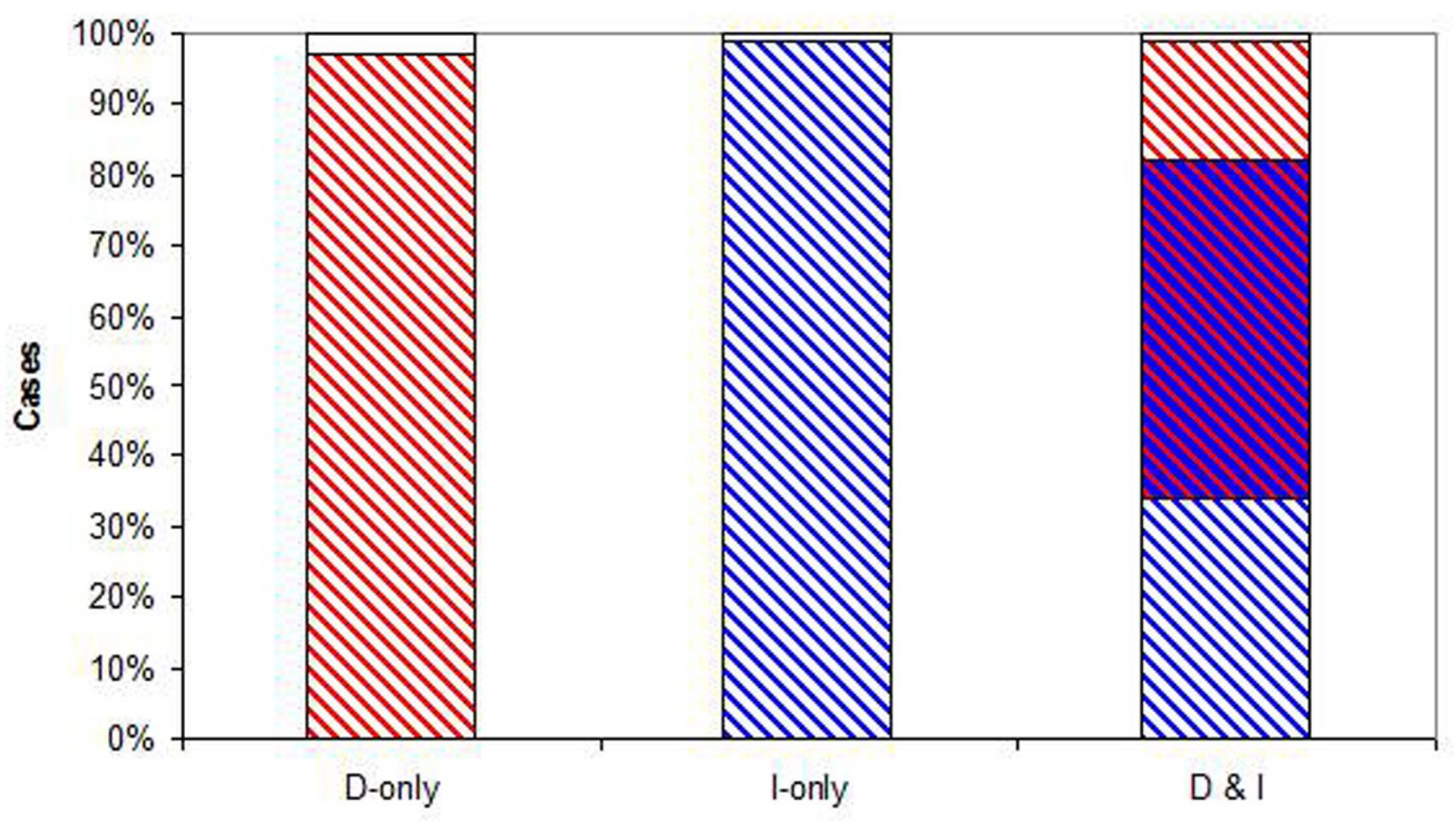




\section{Figure 4}

Behavioral reaction norms of informed dispersal

Reaction Norms for informed dispersal behavior. Solid lines show the reaction norms (black) and 95\% CL (grey) for each form of dispersal. Dashed lines reflect uninformed baseline dispersal. Reaction norms were created using the Informed Dispersal equations with the mean evolved coefficient after 100000 generations. Lines for the 95\% CL were constructed using the variance in evolved coefficients among 100 Monte Carlo runs. Top panels are for models where only one source of information is possible and show dispersal due to A) density dependent dispersal (D-only) and B) immigrant dependent dispersal (I-only). Bottom panels are for models where only both sources of information are possible (D\&I) and show dispersal due to C) density dependent dispersal and D) immigrant dependent dispersal. 


\section{A) Density for D-alone}

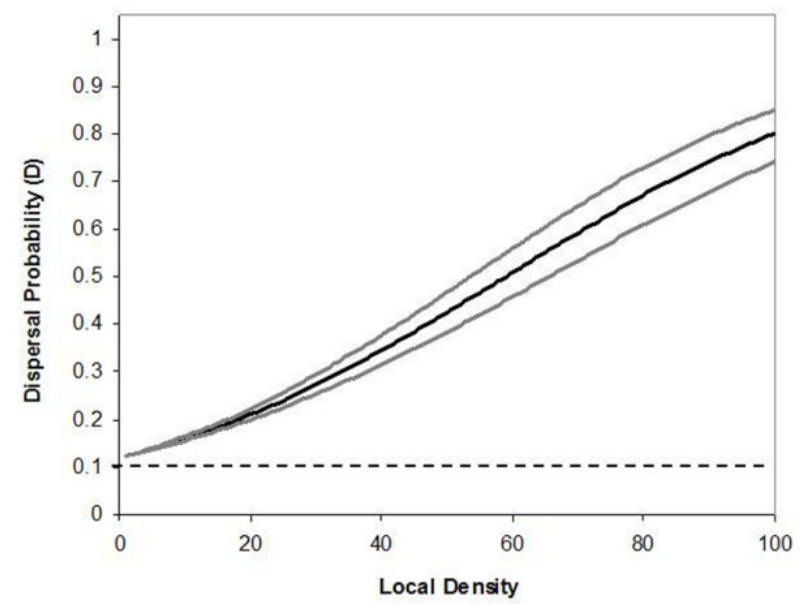

C) Density for D\&I

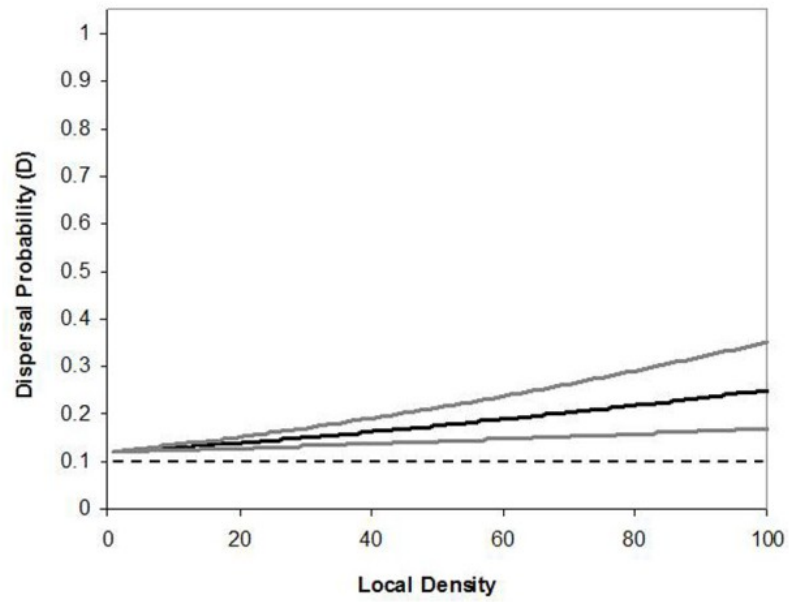

B) Immigrant for l-alone

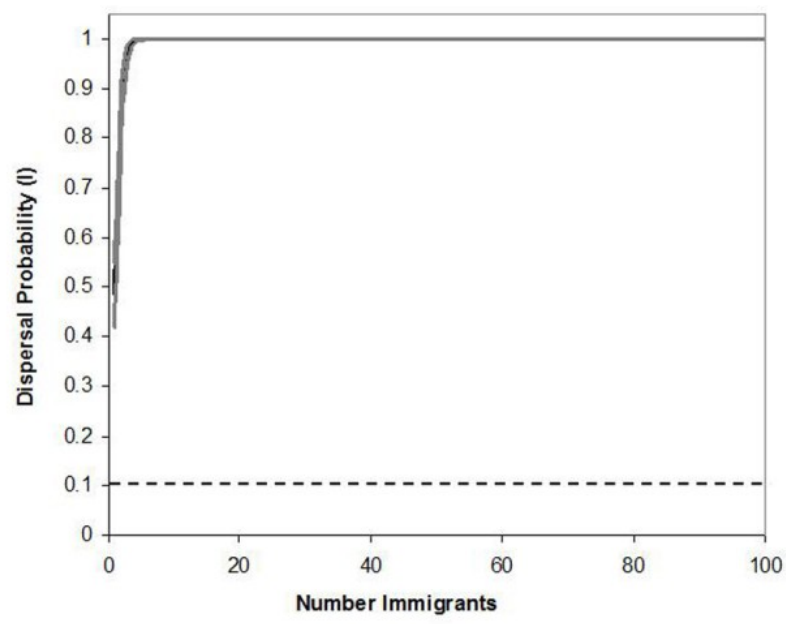

C) Immigrant for D\&I

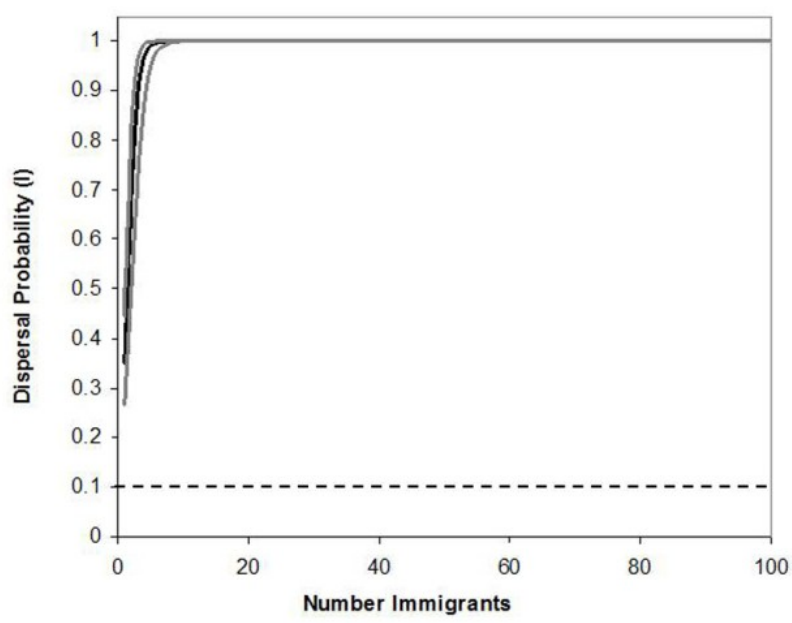




\section{Figure 5}

Benefits of informed dispersal

The relative benefit of dispersal behavior to an individual is estimated by how much better a disperser did by moving (i.e. old pop density/ new pop density, both at reproduction). Shown is the dispersal benefit over the first 100000 time steps for models with low environmental stochasticity (5\% of populations hit) in models A) I-only (D-only is similar) or B) D\&I. Benefits of multiply-informed dispersal (D\&I) relative to using no information or a single source of information (D or I-only) is also observed at the meta-population level by reducing global extinction risk (proportion of 100 Monte Carlo simulations where the metapopulation goes extinct) as stochasticity increases due to C) random environmental stochasticity or D) small population size.

A)

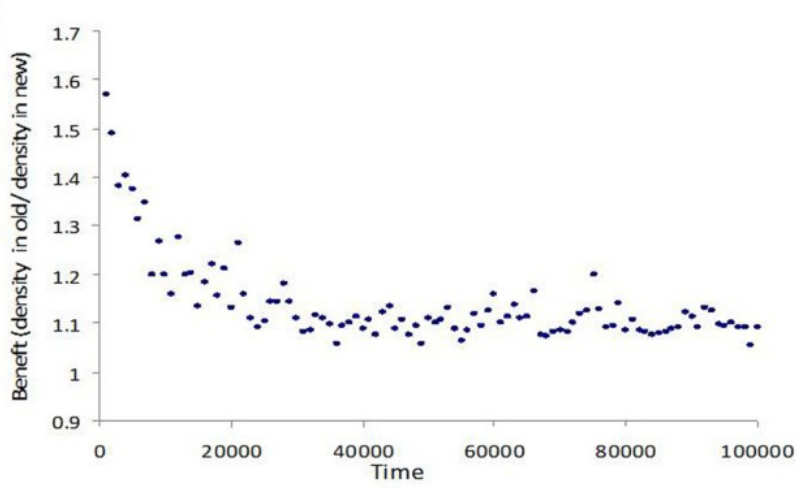

C)

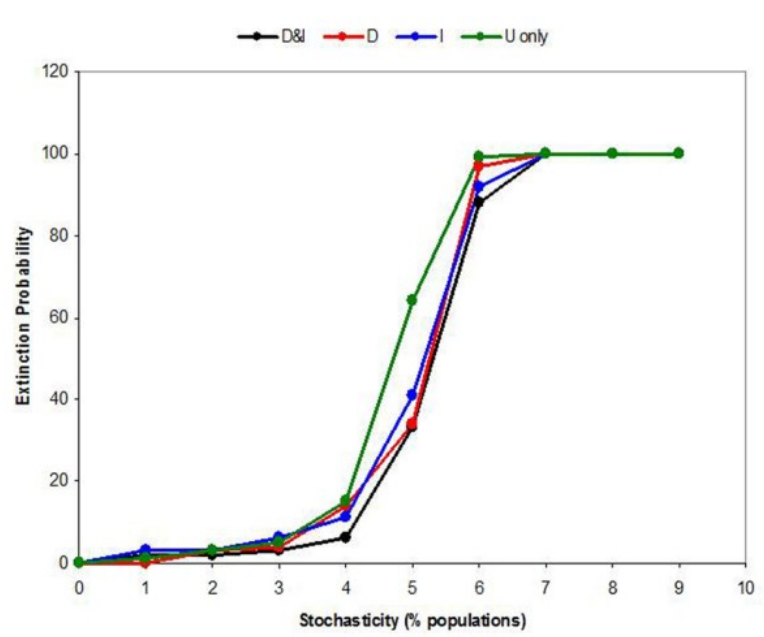

B)

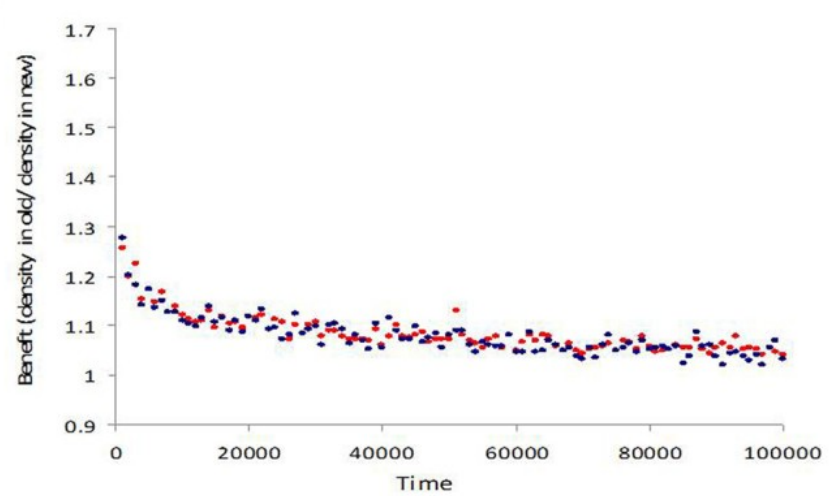

D)

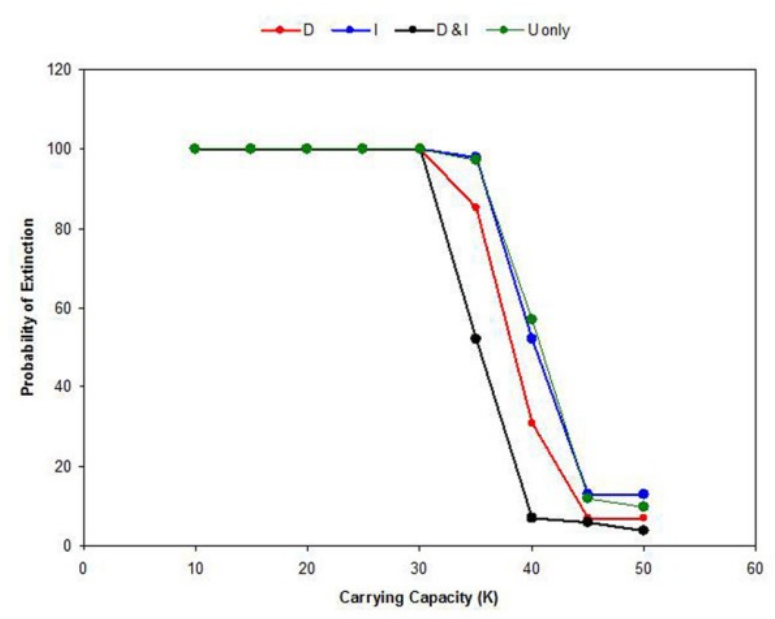

